\title{
Maternally-preset program of apoptosis and caspases involved in execution of the apoptosis at midblastula transition (MBT) but not before in Xenopus laevis embryogenesis
}

\author{
Koichiro Shiokawa \\ Postgraduate School of Judo Therapy, Faculty of Medical Technology, Department of Biosciences, School of Science and Engineer- \\ ing, Teikyo University, Utsunomiya-City, Japan \\ Email: shiokawa@nasu.bio.teikyo-u.ac.jp
}

Received 21 August 2012; revised 23 September 2012; accepted 4 October 2012

\section{ABSTRACT}

To study gene control mechanisms in Xenopus embryos, we analyzed polyamines, cloned SAMDC (Sadenosylmethionine decarboxylase), a key enzyme of polyamine metabolism, and microinjected its mRNA into Xenopus fertilized eggs. The microinjection induced a large increase in SAMDC activity, exhaustion of the substrate SAM (S-adenosylmethionine), and execution of apoptosis at the stage called midblastula transition (MBT). By tracing GFP (green fluorescence protein)-marked apoptotic cells, we reached a conclusion that the apoptosis provides pre-blastula embryos with a fail-safe mechanism of early development. We analyzed caspase mRNAs and found that caspase-9 and -3 mRNAs are maternal mRNA and activation of caspase- 9 is one of the key steps for the execution of the apoptosis. We also found that overexpression of caspase-8, and in addition p53, a tumor suppressor protein, also induces apoptosis at MBT, just like the overexpression of SAMDC and caspase-9 does. The apoptosis induced by $\mathbf{p} 53$ was suppressed by $\mathrm{Xdm}-2$, a negative regulator of $\mathrm{p53}$, and by a peptide inhibitor and a dominant-negative type mutant of caspase-9, but not by those of caspase-8. By contrast, apoptosis induced by SAMDC was suppressed by peptide inhibitors and dominant-negative mutants of both caspase- 9 and caspase-8, but not by Xdm-2. Unlike caspase- 9 mRNA, caspase- 8 mRNA was not a maternal mRNA, but newly expressed during cleavage stage (pre-MBT stage) only in embryos overexpressed with SAMDC. In SAMDC-induced apoptotic embryos activities to process procaspase-8 and procaspase-9 appeared, whereas in p53-induced apoptotic embryos only activity to process procaspase-9 appeared. Thus, Xenopus embryos have at least two pathways to execute the maternal program of apop- tosis: One induced by SAMDC overexpression through activation of caspase-9 and do novo expression of caspase-8 gene, and the other induced by p53 overexpression through activation of caspase-9 but not caspase-8. In Xenopus embryos, it has long been believed that zygotic genes are silent until MBT, but results obtained with caspase- 8 may provide a novel example of gene expression before MBT.

Keywords: Maternal Program of Apoptosis; Midblastula Transition (MBT); Polyamines; S-Adenosylmethionine Decaroboxylase (SAMDC); Xenopus laevis Embryos, Caspases; p53; pre-MBT Transcription

\section{INTRODUCTION}

The normal table of development for Xenopus laevis has been established by Nieuwkoop and Faber [1], in which the development is divided into 66 stages from fertilization to metamorphic climax. The fertilization which is the fusion of two different genome sets is the start of the development of a new life, and the metamorphosis which is characterised by spectacular tail regression is the end of a tadpole to make a juvenile. The development can be roughly divided into four steps: cleavage (segmentation), organogenesis, growth period and metamorphosis [2] (Figure 1). Once the Xenopus egg is fertilized, it begins to divide in about $1.5 \mathrm{hr}$, producing two similar embryonic cells (blastomeres), and after several divisions, becomes a morula. In Xenopus, such rapid cell divisions (cleavage) continue for 12 rounds, and an egg becomes a blastula consisting of ca. 4000 cells, which now has a large internal cavity called blastocoel. After the 12 rounds of cell division, the embryo reaches the stage of midblastula transition (MBT), when the cell cycle aquires $G_{1}$ and $G_{2}$ phases. Active cross-talk of morphogenetic factors starts and the embryo reaches gastrula 


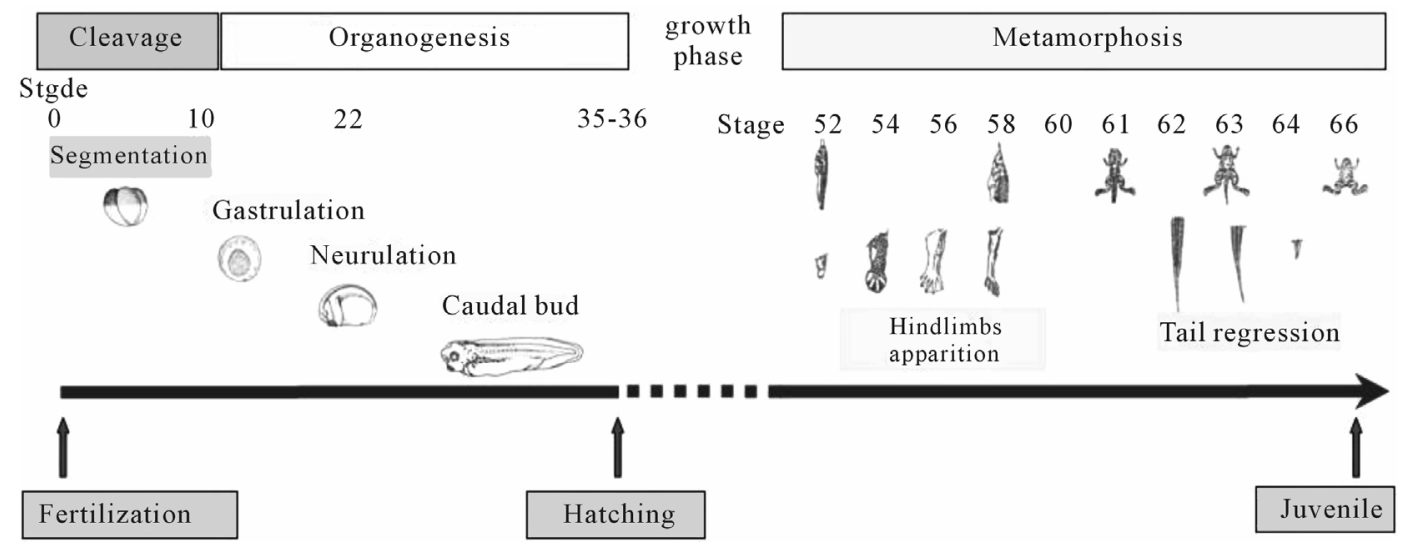

Figure 1. Synoptic view of main developmental stages in Xenopus laevis. MBT takes place between cleavage and organogenesis in this picture. From Estabel et al. [2].

stage (stage 10 to 12.5 ). The morphogenetic movements called gastrulation consist of invagination of Spemann's organizer followed by embryonic induction. On the dorsal part of the embryo, the neuroectoderm is induced by the invaginated dorsal mesoderm, and this phase is the onset of neurulation (stage 13). At this stage, the neural tube is formed, which becomes the origin of brain, neural crest and spinal cord. In the neurula the axial mesoderm differentiate to form origins of skeleton, muscles, kidneys, heart and circulatory system, and gonads. The endoderm whose cells still have a large amount of yolk granules in their cytoplasm becomes the origin of endodermal organs such as digestive tract and lungs. Along with these changes, the embryo is elongated, reaches the tailbud stage, and after hatching, becomes a tadpole.

In vertebrates, Glucksman [3] first reported cell death during the development. Cell death was observed at blastocyst stages in mammals, as well as during gastrulation in the urodelan amphibian Cynops pyrrhogaster [4]. Apoptosis was detected in most vertebrates as programmed cell death in later embryos particularally during the development of the nervous system, although as described below, recent studies were devoted to the detection of apoptosis at very early stages of development [5-12]. In Xenopus nervous system, Hensey and Gautier [8] detected apoptotic cells in brain, eyes, spinal cord, and developing tail at the beginning of tail-bud stages (stages 21 to 28). Apoptotic cells were also observed in the central nervous system, particularly in the telencephalon, diencephalon and mesencephalon from stages 29 to 35 , possibly related to the acquisition of the definitive form and structure of the brain, [13]. In Xenopus early neurulae, a gene called XHR1 has been cloned which defines later the region where apoptosis or programmed cell death occur for segmentation in brains [14]. At around stage 52, tadpoles start metamorphosis. At the onset of metamorphosis, the spinal cord contains numerous apoptotic cells, principally in the interneuron area, and many cells of the caudal spinal ganglia also undergo apoptosis [15]. During climax, caspase-3 activity increases in the spinal cord [16]. The frequency of apoptotic cells becomes peak at stage 58 tadpole stage in the spinal cord [15], and muscles of the tail regress totally by programmed cell death [17]. Caspase-3 activity increased in muscle cells during the climax stages [18].

In the early embryonic development of Xenopus laevis midblastula transition (MBT) occurs after 12 cycles of cleavage in $[19,20]$, which is a time when embryos shift from the phase of low (per embryo) transcription [21-24], or the phase of development driven mainly by maternal stockpiles, to the phase of high (per embryo) transcripttion or the phase driven mainly by gene products newly produced based on the zygotic nuclei. During the preMBT stage or the cleavage stage, cell divisions are rapid without $G_{1}$ and $G_{2}$ phases in the cell cycle. This is because the Xenopus egg is a huge cell provided in its cytoplasm with an extremely large amounts of maternal stockpiles and the egg can keep dividing without synthesizing materials necessary for cell divisions. It is true that maternal mRNAs in the oocyte provide most of the information necessary for harmonious development from cleavage to MBT and to gastrula stage. However, this does not necessarily implies that transcription should be turned off during the cleavage. Thus, during this period, cells produce a few RNAs [21-24], although cells in this cleavage stage embryo have long been believed to be transcriptionally totally silent [20]. The reason for the difficulty to detect the synthesis of mRNA and other small RNAs during the cleavage stage is mainly the small number of cells constituting the embryo: For example, a late blastula in which transcription could easily be detected consists of 4000 to 8000 cells (nuclei), whereas a 64-celled embryo at the cleavage stage consists of only 64 cells (nuclei).

After the MBT stage (4096 cells/embryo), when $\mathrm{G}_{1}$ and $G_{2}$ phases reappear in the cell cycle, various changes 
in cellular activities take place [25]. Thus, cell division becomes asynchronous $[19,20,26]$, and cells acquire motility $[20,27]$, and cell cycles shift from checkpoint-unregulated to checkpoint-regulated ones $[28,29]$. At MBT, transcriptional activity from zygotic nuclei is reportedly very high. In fact, a strong activation of transcription from zygotic nuclei takes place at the MBT: Quantitative measurements revealed that the transcriptional activity to form heterogeneous mRNA-like RNA at MBT is ca. 100 -folds (on a per-nucleus basis) of the activity of the cells of the later stage embryos (e.g. gastrula and neurula cells). On the other hand, rRNA transcription does not occur during the cleavage stage. Instead, it starts only at and after MBT, and once it starts its rate per nucleus is constant in later stage embryos [30,31]. As the cytologycal manifestation of the rRNA synthesis, nucleoli start to be formed from the MBT stage [32]. The transcriptional activation during the cleavage stage (pre-MBT stage) is also proved for transcription from exogenously-introduced genes like bacterial CAT (chloramphenicole acetyltransferase) genes [33], although this was once also reported and accepted to be expressed only at and after MBT, but not before [34]. The elongation of the cell cycle after the MBT which is due to the appearance of $\mathrm{G}_{1}$ and $G_{2}$ phases may be regulated by the activation of Xchk1 kinase [28], which is essential in remodelling the cell cycle after MBT $[28,35,36]$.

In this review article, I describe our studies on the unique polyamine composition followed by cDNA cloning of S-adenosylmethionine decarboxylase (SAMDC), and the results derived from the microinjection of its mRNA into Xenopus fertilized eggs, which quite unexpectedly induced massive cell dissociation, which turned out to be due to the execution of the maternally-preset program of apoptosis. I then proceed to describe our experiments to microinject the SAMDC mRNA into only one blastomere at 8- to 32-cell stage embryos, and to trace the fate of the injected cells. The results obtained lead us to conclude that the apoptosis which is executed so early in the development is a kind of "fail-safe" mechanism to check and eliminate damaged cells before embryos enter the morphogenic phase after the MBT stage. In the latter half of this article I describe the results of analyses on mRNAs of caspases 9 and 8 which were found to be involved in the maternal program of apoptosis. It appeared here that in SAMDC-overexpressed embryos, de novo synthesis of caspase- 8 mRNA takes place at cleavage stage. Based on the results obtained, we conclude that Xenopus embryos have at least two pathways to execute the maternal program of apoptosis; one executed by SAMDC-overexpression, and the other executed by p53-overexpression, and while the former is executed through activation of caspase- 8 before the activation of caspase- 9 , the latter is activated not through caspase- 8 but directly through caspase-9.

\section{RESULTS AND DISCUSSION}

\subsection{Polyamines and SAMDC (S-Adenosylmethionine Decarboxylase) Cloning in Xenopus Embryos}

Natural polyamines (putrescine, spermidine, and spermine) occur ubiquitously in both prokaryotic and eukaryotic cells [37], and polyamine biosynthesis is regulated also by polyamines themselves [38]. Prokaryotic cells like Escherichia coli have a high content of putrescine and spermidine, with no detectable amount of spermine. The absence of spermine in $E$. coli cells is due to the lack of spermine synthase, an enzyme which converts spermidine into spermine [39]. Eukaryotic cells, by contrast, have the enzyme spermine synthase, and hence have a relatively high content of spermine [40].

Various studied have been performed on polyamines in oocytes and embryos of mouse [41], chick [42], sea urchin [43], poychete [44], and Drosophila [45]. In amphibians, especially in Xenopus laevis, amounts of polyamines have been determined during oogenesis [46, 47], oocyte maturation [47-49], and early embryogenesis [47,50-52]. In Xenopus oogenesis, levels of putrescine, spermidine, and spermine keeps increasing, and at the end of the oogenesis, the level of spermine decreases abruptly, and further decreases during maturation (from $4 \mathrm{hr}$ after the administration of progesterone). As a result, the level of spermine reaches a very low level in the end of maturation, and also from fertilization through tadpole stage, the level of spermine remains low (less than 0.1 nmole per embryo) [47,50,51]. On the other hand, levels of putrescine and spermidine are much higher from oogenesis through early embryogenesis [47,53]; the amount of putrescine being more than twice that of spermidine throughout stages. Thus, polyamine composition in Xenopus early embryos is apparently similar to that of bacteria.

Both spermidine synthase and spermine synthase are constitutively synthesized [54], and therefore, ornithine decarboxylase (ODC) and S-adenosylmethionine decarboxylase (SAMDC) are key enzymes which are ratelimiting in polyamine biosynthesis. ODC produces putrescine from ornithine by eliminating its carboxyl group, whereas SAMDC decarboxylates S-adenosylmethionine (SAM ) and produces decarboxylated SAM (dcSAM), which provides cells with the aminopropyl group necessary to form spermidine and spermine from putrescine and spermidine, respectively.

We screened a Xenopus tailbud cDNA library using the human SAMDC cDNA as a probe and isolated Xenopus SAMDC cDNA (1030 bp). We examined the changing level of SAMDC mRNA by Northern blot 
analysis in growing oocytes, oocytes during maturation, and developing embryos at various stages, and found that the signal for SAMDC mRNA $(3.5 \mathrm{~Kb})$ was detected at all the stages examined. The level of SAMDC mRNA was relatively high from the earliest stage of oogenesis, but after fertilization, decreases until the early neurula stage, and again increases after tailbud stage [47,52]. The level of SAMDC activity was quite low both at the cleavage and early neurula stage, and it starts to increase only at the early tadpole stage, although another key enzyme, ODC increases in its level shortly after MBT [51].

\subsection{Overexpression of SAMDC mRNA in Xenopus Embryos and Discovery of Sudden Cell Dissociation at MBT}

To test if the SAMDC mRNA obtained from the cDNA is functional, we in vitro-transcribed mRNA from the cDNA, and microinjected the mRNA (1 ng/egg) into Xenopus fertilized eggs. The mRNA-injected embryos cleaved and developed quite normally up to the blastula stage, but at the mid to late blastula stage (shortly after MBT), all the embryos suddenly underwent cell dissociation (Figure 2). These embryos were soon dissolved completely due to osmotic shock [7]. When we co-injected beta-galactosidase mRNA and SAMDC mRNA into fertilized eggs, only cells which expressed beta-galactosidase were dissociated (Figure 3). When we coinjected mRNAs for GFP (green fluorescent protein) and SAMDC into only one blastomere of 2-celled embryos, only a half portion of embryos which expressed GFP was dissociated at the late blastula stage (Figure 4). Then, it

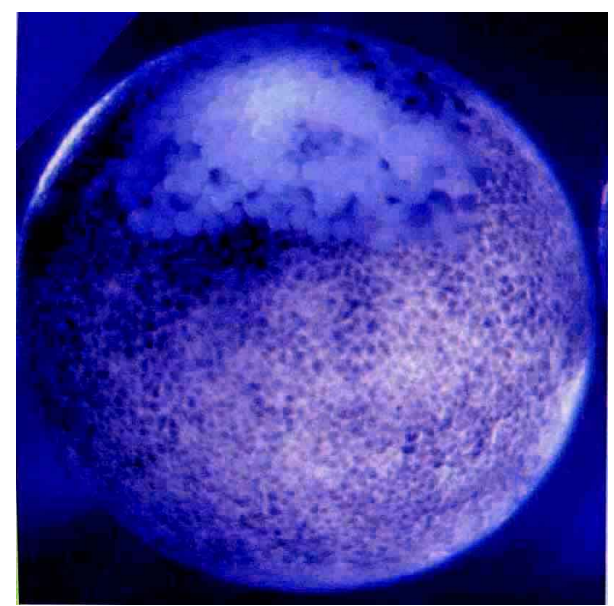

Figure 2. Apoptosis induced by SAMDC overexoression. Fertilized eggs were injected with Xenopus SAMDC mRNA (100 pg), and cultured in isotonic $1 \times$ Steinberg's solution to protect dissociated cells from a osmotic shock. Embryos were filmed at late blastula stage. Dissociated cells appeared in the mRNA-injected region. From Shibata et al. [7].

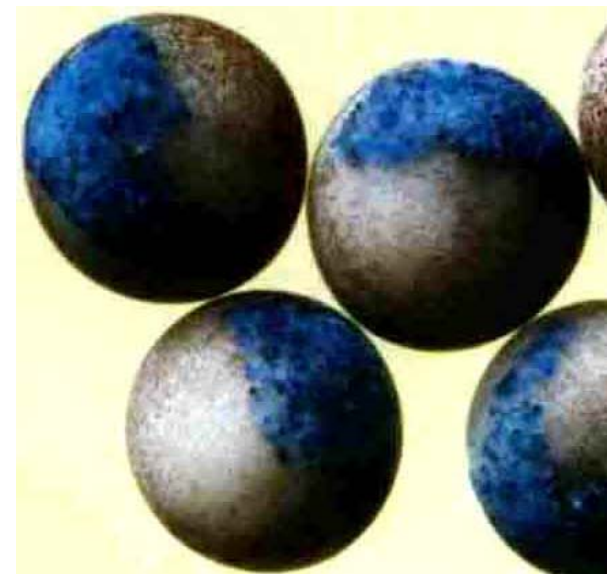

Figure 3. Beta-Galactosidase marking of dissociated cells. Fertilized eggs were injected with $0.5 \mathrm{ng} / \mathrm{egg}$ each of beta-galactosidase mRNA and SAMDC mRNA. Only cells stained with X-gal were dissociated. From Shibata et al. [7].

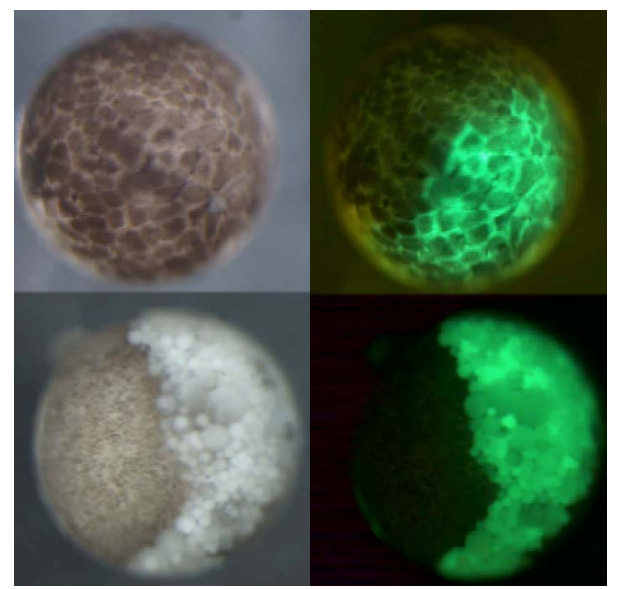

Figure 4. Apoptosis is induced not at early blastula stage but at late blastula stage, or after MBT. Only one blastomere of a 2-celled embryo was co-injected with SAMDC mRNA (1 ng/egg) and GFP mRNA (100 pg/egg), and embryos were filmed at early blastula (top two) and early gastrula (bottom two) stages using the visible light (left two) and UV light (right two) [Kuroyanagi S, Shiokawa K, unpublished].

was apparent that the injection of SAMDC mRNA was the cause of the sudden cell dissociation.

When sectioned materials of these SAMDC-overexpressed embryos were examined at early blastula stage, there was no difference in the appearance of blastoceol and arrangement of cells between the control and the SAMDC-injected embryos. At late blastula stage, however, a large number of dissociated cells were found in the blastoceol. The percentage of embryos which underwent the cell dissociation was dosage-dependently changed 
between $0.01 \mathrm{ng} / \mathrm{egg}$ and $10 \mathrm{ng} / \mathrm{egg}$, and in this wide range of the dosage, the timing of the cell dissociation was constant: The cell dissociation took place always at shortly after MBT, but not before. Injection of mRNAs other than SAMDC mRNA, such as Xenopus type IIA activin receptor, a Xenopus RNA-binding protein (nrp-1), and Xenopus initiation factor eIF4E had no effect, and SAMDC mRNA (1 ng/egg) without a cap structure was also not effective, indicating that the cell autonomous dissociation observed was due to the specific function of the injected SAMDC mRNA.

Using ${ }^{3} \mathrm{H}$-thymidine, ${ }^{3} \mathrm{H}$-uridine and ${ }^{14} \mathrm{C}$-leucine to label DNA, RNA and protein, respectively, we found that protein synthesis was the first to be inhibited in the SAMDC-overexpressed embryos and the inhibition was detected at early blastula stage before the initiation of cell dissociation. Since the endogenous SAMDC mRNA was estimated as $0.005 \mathrm{ng}$ or less per embryo, injection of $1 \mathrm{ng} / \mathrm{egg}$ of SAMDC mRNA resulted in overexpression of SAMDC mRNA at least 200-folds, and this resulted in ca. 400-folds of the increase in SAMDC enzyme activity. In the SAMDC mRNA-injected embryos, the high level of SAMDC mRNA was maintained until the blastula stage, but it was reduced to the background level by the gastrula stage. This SAMDC overexpression exerted little influence on the polyamine composition within the embryo [47], probably because we did not simultaneously overexpress the spermidine synthase and spermine synthase. The cell dissociating effect of SAMDC mRNA was completely abolished by co-injecttion of EGBG (ethylglyoxal-bis-guanylhydrazone) (20 pmoles/egg), a specific inhibitor of SAMDC $[38,55]$. We found here that the intracellular level of SAM was reduced by more than $80 \%$ by the SAMDC mRNA injecttion, and when SAM was co-injected with SAMDC mRNA, embryos were completely rescued (Figure 5). Therefore, we concluded that injection of SAMDC mRNA induces SAM deficiency and this was the primary cause of the induction of the massive cell dissociation.

\subsection{The Cell Dissociation Is Due to Apoptosis}

The evidence that the cell dissociation observed was due to execution of apoptosisis is as follows. First, electron microscopic analyses revealed that nuclei of SAMDC mRNA-induced dissociated cells were fragmented into two or three portions and then further fragmented [9] (Figure 6). In such SAMDC mRNA-injected embryos, a large number of cells became TUNEL-positive (Figure 7), and furthermore, DNA extracted therefrom formed "ladders" on agarose gels [9]. We first injected SAMDC mRNA into uncleaved fertilized eggs, and at the 2-cell stage further injected into only one of the blastomeres a

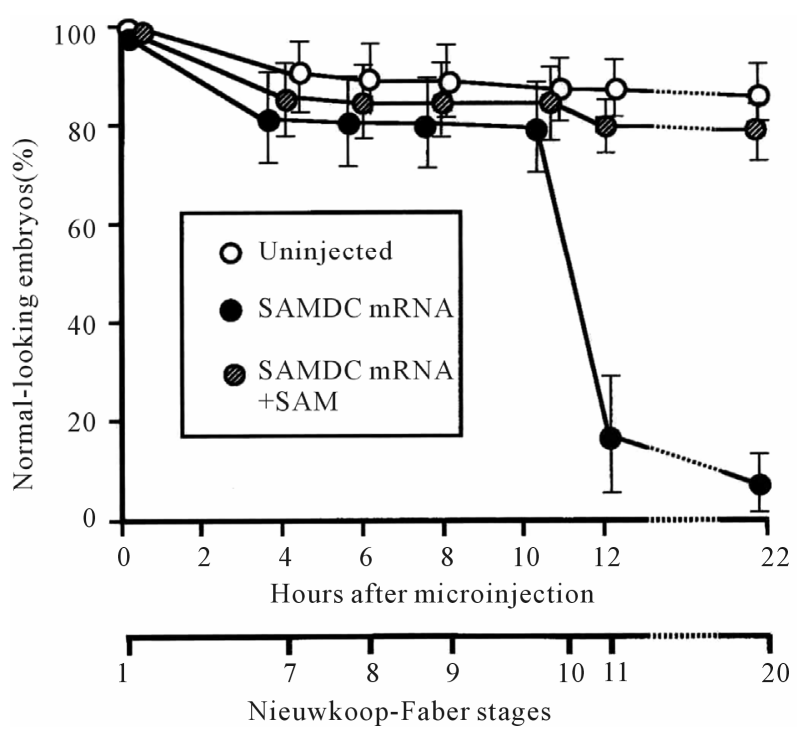

Figure 5. Rescue of embryos from cell dissociation by SAM. Fertilized eggs were injected with either SAMDC mRNA (0.1 ng/egg) alone or SAMDC mRNA (0.1 ng/egg) plus SAM (200 pmoles/egg) and percentages of normally developing embryos were plotted. From Shibata et al. [7].

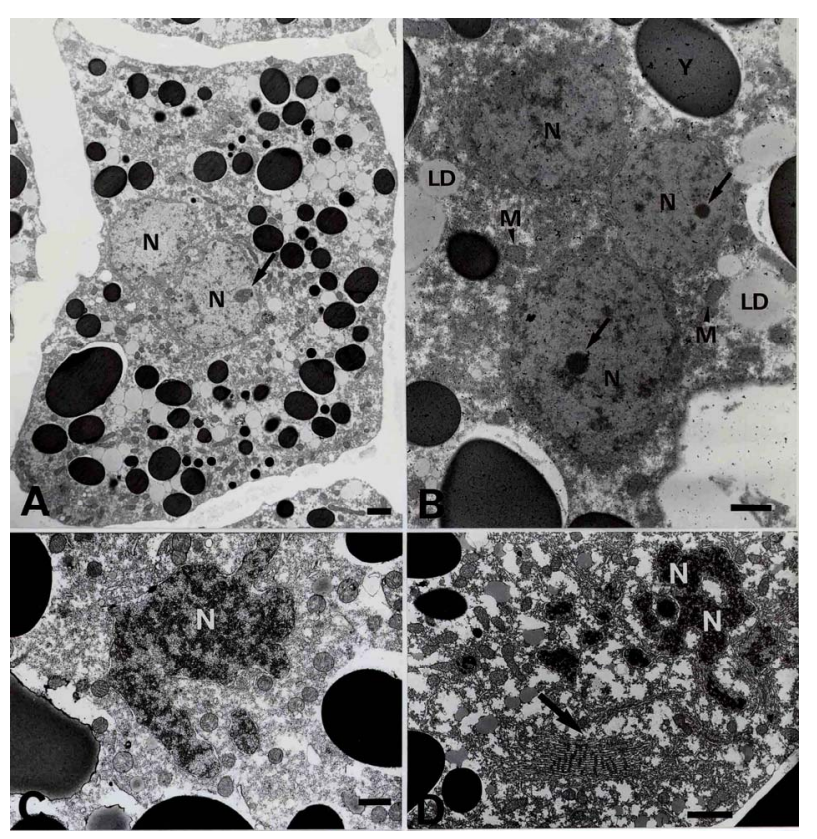

Figure 6. Electron microscopic pictures of dissociated cells. Fertilized eggs were injected with SAMDC mRNA (1 ng/egg) and cultured in $1 \times$ Steinberg' solution to protect from osmotic shock and examined at early gastrula stage (A), (B) or midgestrula stage (C), (D). Scale bars are $2 \mu \mathrm{m}$. N, nucleus; LD, lipid droplet; M, mitochondria. Kai et al. [9].

mixture of GFP mRNA and Xenopus Bcl-2 mRNA, as an anti-apoptotic factor that suppresses the release of cytochrome $\mathrm{c}$ from mitochondria $[56,58]$. We found here that cell dissociation was suppressed only in the GFP-positive and hence Bcl-2-expressing half embryo [9]. When we 


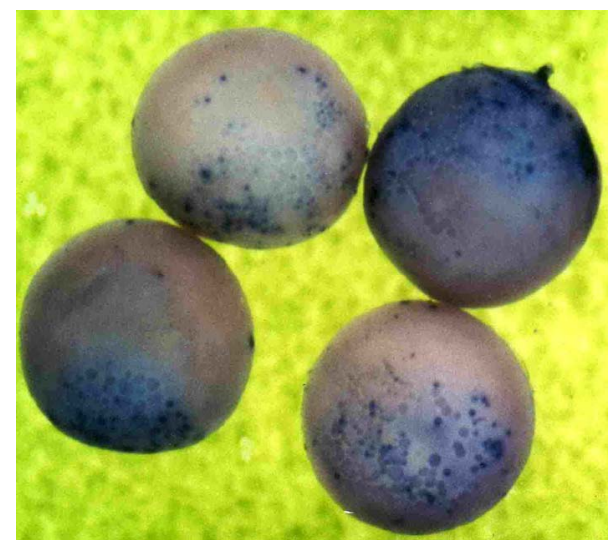

Figure 7. TUNEL staining of SAMDC mRNAinjected embryos. Embryos were injected with SAMDC mRNA (1 ng) and examined for TUNEL reaction at early gastrula stage. Kai et al. [9].

injected Bcl-2 mRNA and SAMDC mRNA together into uncleaved fertilized eggs, all the embryos were found to escape the cell dissociation and about half of such rescued embryos became normal tadpoles (Figure 8). These results indicated that the dissociation observed was due to execution of apoptosis.

While we were analyzing the SAMDC-induced apoptosis, various toxic agents, such as gamma-ray $[6,12]$, hydroxyurea [59], cycloheximide [6,59], and alphaamanitin $[5,6]$ were reported to induce similar apoptosis in Xenopus blastulae. Sible et al. [5] and Hensey and Gautier [6] reported that injection of Bcl-2 mRNA retarded the onset of apoptosis by $2-3 \mathrm{hr}$. However, such rescued embryos were then dissociated and died. When we injected 5-aza-2' deoxycytidine (5-Aza-CdR) which induces hypomethylation of DNA and 5-methyl-2'-deoxycitidine-triphosphate (5-methyl dCTP) which induces hypermethylation of DNA [60], embryos developed normally up to MBT, but they were dissociated and died due to apoptosis. When Bcl-2 mRNA was co-injected with these inhibitors of methylation, Bcl-2 here again only postponed the cell dissociation by $2-3 \mathrm{hr}$. Therefore, the complete rescue which was realized by Bcl-2 in the SAMDC-induced embryos is interesting. Probably, the reason for the complete rescue is due to the disappearance of the overexpressed SAMDC due to its metabolic instability [61].

\subsection{The Apoptosis May Be a Fail-Safe Mechanism of Early Development for Embryos to Proceed beyond MBT}

To obtain some idea about the developmental significance of the apoptosis executed at such an early stage of development, we examined embryos that had been injected with either wild-type SAMDC mRNA or artifi-

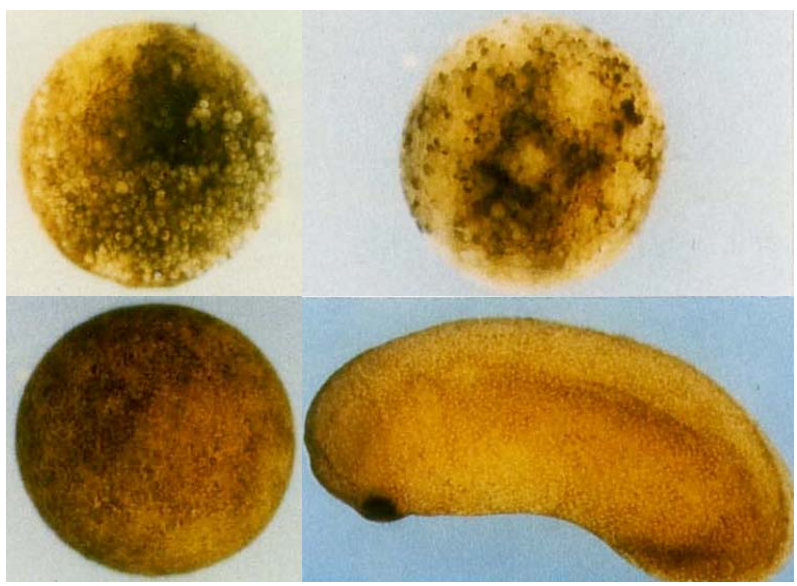

Figure 8. Rescue of SAMDC mRNA-injected embryos by Bcl-2 mRNA. Fertilized eggs were injected with $0.5 \mathrm{ng}$ of SAMDC mRNA and cultured in $1 \times$ Steinberg's solution. Control cells were dissociated at early gastrula stage (Top, left), and remained dissociated (Top, right) when rescued embryos reached tailbud stage. Fertilized eggs co-injected with $0.5 \mathrm{ng}$ of SAMDC mRNA and $2 \mathrm{ng}$ of Bcl-2 mRNA were not dissociated at early gastrula stage (Bottom, left) and reached the tailbud stage (Bottom, right). From Kai et al. [9].

cially mutated, non-effective (defective), SAMDC mRNA into only one blastomere of embryos at $16-32$ cell stages. In this experiment both types of mRNAs were mixed with GFP mRNA as a lineage tracer, so that the descendant cells of the injected blastomere could be traced. All the embryos injected with wild-type SAMDC mRNA into one of their blastomeres at these stages became tadpoles, without showing any sign of cell dissociation (apoptosis) at MBT at least in their outer appearance [61]. At late blastula stage, however, luminescent cells which had been recognized on the surface of the embryo disappeared from the wild-type mRNA-injected embryos, whereas widely-spread luminescent cells remained on the surface of embryos injected with the defective SAMDC mRNA [61]. To trace the luminrscent cells we dissected the embryos and examined the inside of the embryo. Here, we found many dissociated luminescent cells within the blastocoel in the wild-type mRNA-injected embryos, but not in the defective mRNAinjected embryos. The occurrence of dissociated cells inside the blastocoel was also confirmed in the sectioned materials. Thus, it appears that the blastocoel provides not only the space into which mesodermal cells invaginate, but also the space for apoptotic cells to be separated and to undergo apoptosis [61].

We examined these embryos also at the tadpole stage. We found that whole body of the mutant mRNA-injected tadpoles were green in the UV light due to the presence within the embryo of many luminescent cells throughout the body. By a sharp contrast, no luminescent cells remained in the wild-type mRNA-injected tadpoles. Inter- 
esting here was that tadpoles derived from wild-type mRNA-injected embryos were shorter in body length, and sometimes even abnormal, having small head (sometimes acephaly), small trunk and tail, and body axisbending. The execution of apoptosis at MBT and the size of the tadpoles which survived and developed beyond MBT in these experiments can schematically shown as in Figure 9. As Hensey and Gautier [8] pointed out, cells in Xenopus early embryos may check themselves at MBT to see if they are capable of continuing further development. If some cells find themselves physiologically aberrant, they disappear from the embryo by executing the apoptotic program (Figure 10). The cellular activities to be checked here seem to include intactness of DNA structure, occurrence of DNA replication, and DNA methylation, normal RNA transcription, and translation, or protein synthesis, and the level of SAM, as expected from the results summarized above. We assume that this apoptosis constitutes a surveillance or a "fail-safe" mechanism for normal development to check and eliminate damaged cells at MBT when $\mathrm{G}_{1}$ phase first appears in the cell cycle in order to save the rest of the embryo and permit them to continue the development $[61,62]$.
Similar apoptotic cell death has been reported in zebra-fish embryos [63].

\subsection{Possible Mechanism of the Execution of the Apoptosis at MBT, but Not before}

One question which arises here is the reason why the embryonic apoptosis is executed at MBT but not before. There have been several experimental challenges about this [2]. One possible approach could be related to DNA methylation control. It has been reported that DNA methylation supported by methyltransferase cDnmt1P might control the switching on-off of apoptosis in cleavage stage [64]. This is because the depletion of this enzyme appears to activate Xenopus p53 system which is related to apoptosis. Another pathway may involve a signal provided by members of BMP (bone morphogenetic protein) family. The Xenopus protein Smad8 (xSmad8) is a intracellular mediator of BMP signalling, carrying the signal from the cytoplasm to the target DNA within the nucleus. Depletion of xSmad8 in embryos causes apoptosis [65]. Segmentation was observed in xSmad8-depleted embryos, but these embryos could not deveop beyond gastrulation and died. Another molecule, Bix3, is also

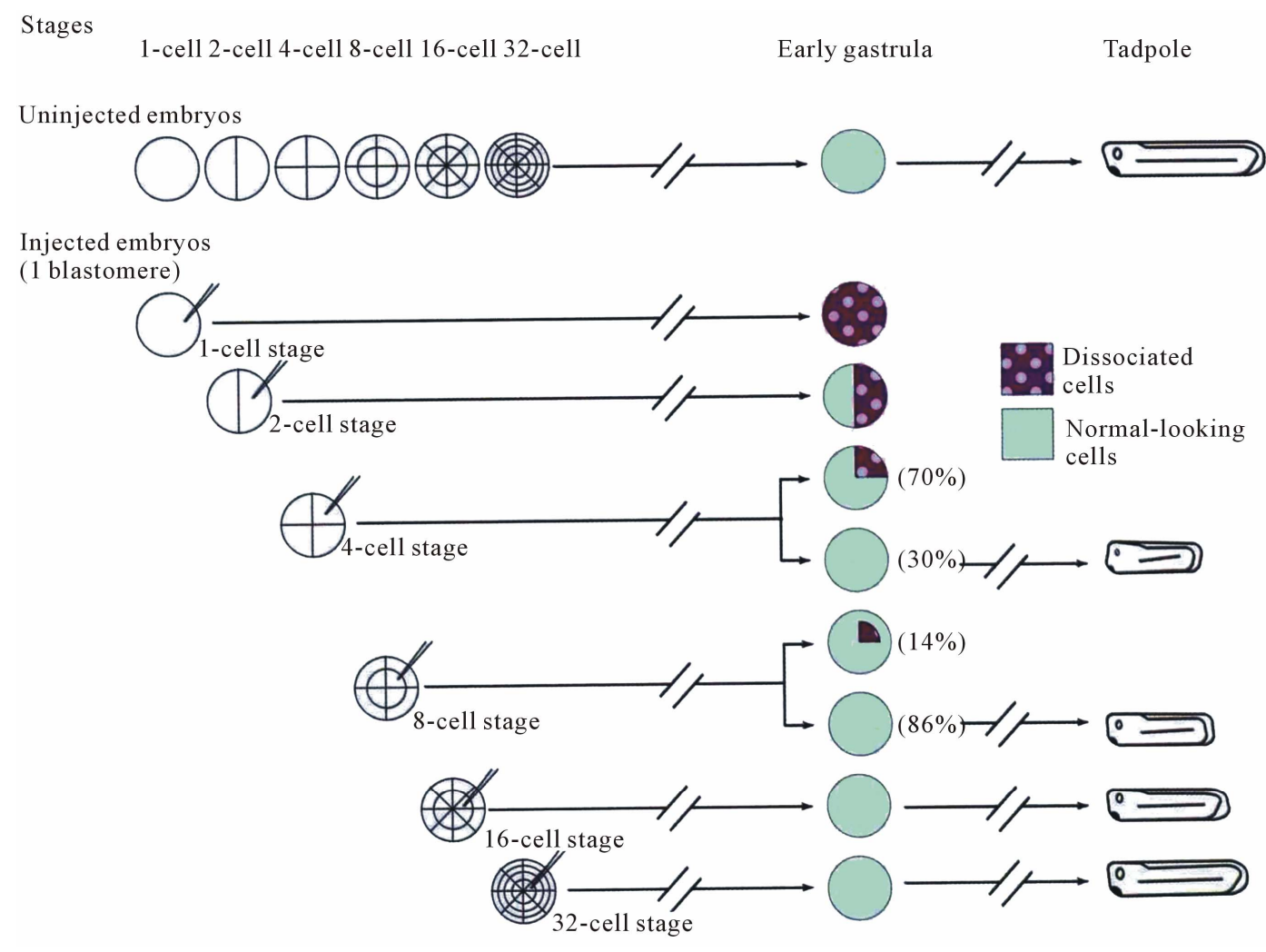

Figure 9. Experimental design and results of injection of SAMDC into only one of the blastomeres at different stages. SAMDC mRNA was injected into only one blastomere at different stages and cultured. The amount of SAMDC mRNA was adjusted so that the concentration of the mRNA in the cytoplasm of the injected cell was approximately the same $(0.5 \mathrm{ng} / 1$ micro liter; 1 micro liter is the approximate volume of an egg). Red marks indicate the cell dissociation which takes place at MBT. From Kai et al. [61]. 


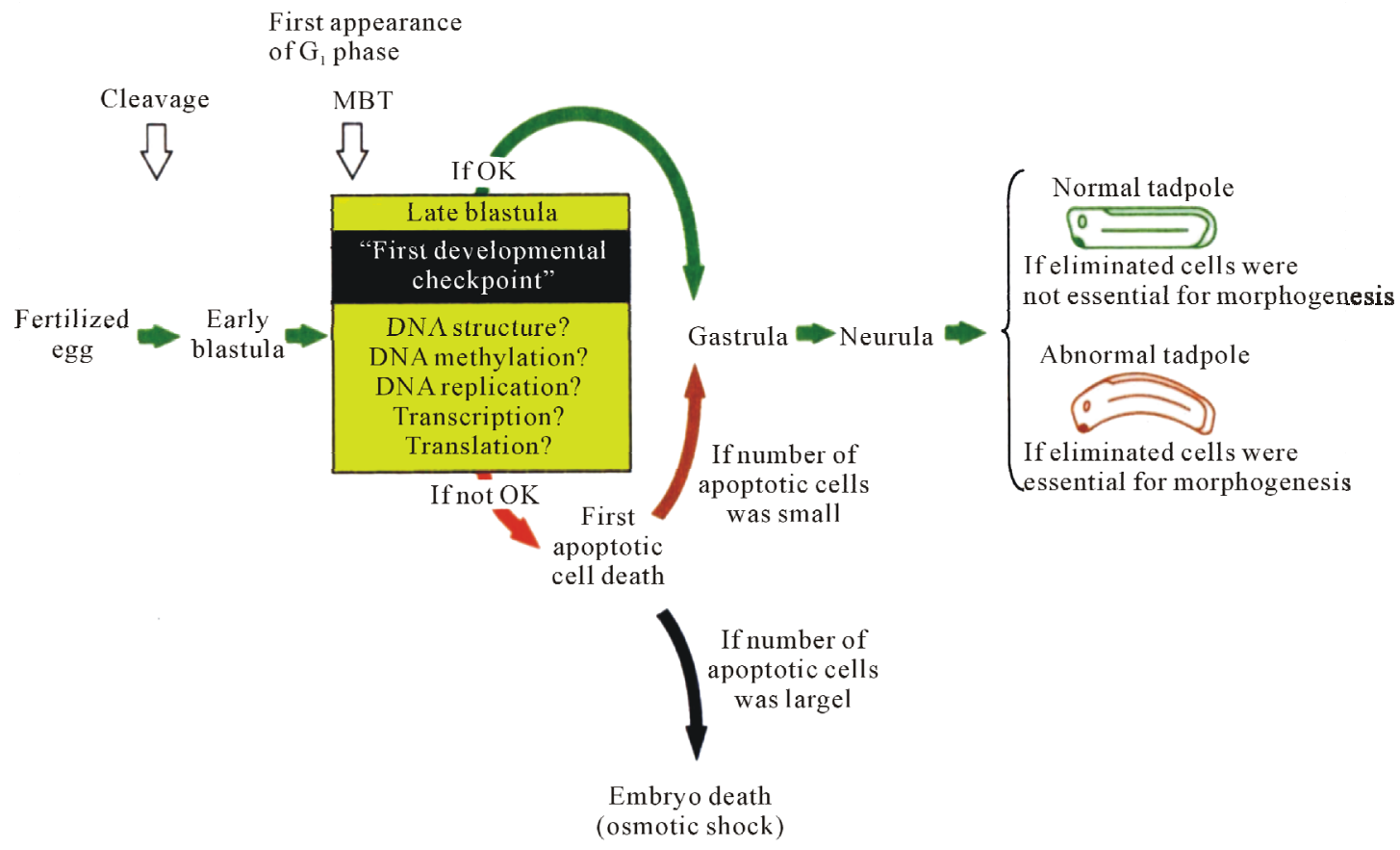

Figure 10. A model which shows how early development proceeds. This model suggests possible occurrence of apoptotic check point which functions as a surveillance or "fail-safe" mechanism in Xenopus early embryonic development. Fertilized eggs cleave rapidly until the early blastula stage. At MBT, the "first developmental checkpoint" comes when $\mathrm{G}_{1}$ phase first appears. We assume that this check mechanism determines cell-autonomously if the cell continues development. However, even when apoptosis was executed, embryos follow two different courses. If the number of apoptotic cells was large, the whole embryo stops development and dies. If the number of apoptotic cells was small, apoptotic cells are confined within the blastocoel and the embryo itself continues on development. From Kai et al. [61].

expected to regulate cell death. The overexpression of this molecule in the vegetal hemispheres of early embryos triggered the apoptosis of embryonic cells [66]. In oocytes and in early embryos up to stage 8 (midblastula), the maternal survivin mRNAs are strongly expressed [67]. This molecule may be a member of the IAP (inhibitors of apoptosis) family, and could be one of the proteins that control programmed cell death in such a way that its execution is not permitted until MBT. After the increase in zygotic transcription at MBT, the amount of maternal survivin mRNAs is reported to decrease quickly, and this decline may be necessary for the execution of the apoptosis. If this is correct, survivin could be a maternal inhibitor of apoptosis, which suppresses the execution of the apoptosis before MBT.

\subsection{Involvement of Caspase 9 in SAMDC mRNA-Induced Apoptosis}

The unique enzymes involved in the execution of apoptosis are caspases which constitute a cysteine protease gene family [68]. Previous studies showed that cell lysates of hydroxyurea-treated or gamma-ray-irradiated Xenopus embryos have activity to cleave poly-ADPribose polymerase (PARP) [6,59], a substrate of most of caspases, including caspases-3 and 7 [68]. Also, it has been reported that the synthetic peptide, which possibly inhibits caspase- 9 and caspase-3, partially blocks or delays the onset of apoptosis induced by gamma ray-rradiation or cycloheximide treatment $[6,59]$.

We first tested if caspase-9 is involved in the apoptosis which is activated so early in the development in SAMDC-overexpressing Xenopus embryos. Here, we microinjected different doses of synthetic peptide-inhibitors for caspase-9 (Ac-LEHD-CHO) and caspase-1 (Ac-YVAD-CHO) into Xenopus fertilized eggs together with SAMDC mRNA (200 pg/egg). The peptide-inhibittor for caspase-9 suppressed the SAMDC mRNA-induced apoptosis at 2000 and 200 pmoles/egg, and rescued embryos developed to neurula and even to swimming tadpole stage (Figure 11, left). By contrast, the peptide inhibitor for caspase-1 suppressed the induction of apoptosis only slightly at 2000 pmoles/egg, but all the embryos partially rescued here died before they reached the neurula stage.

It is known that caspase-9 without the active site binds to Apaf-1 and functions as dominant-negative caspase-9 [69]. It is also known that caspase-1 whose cysteine in the active site was converted to glycine can work as a 


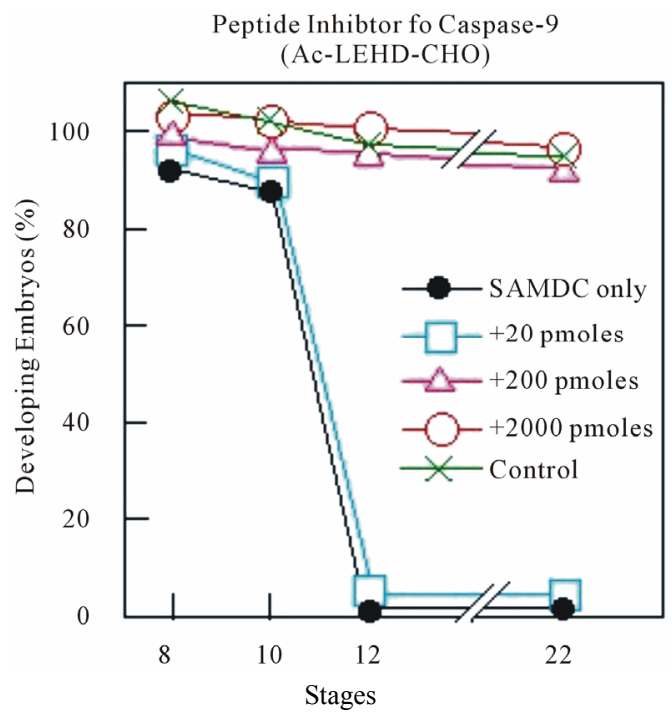

(a)

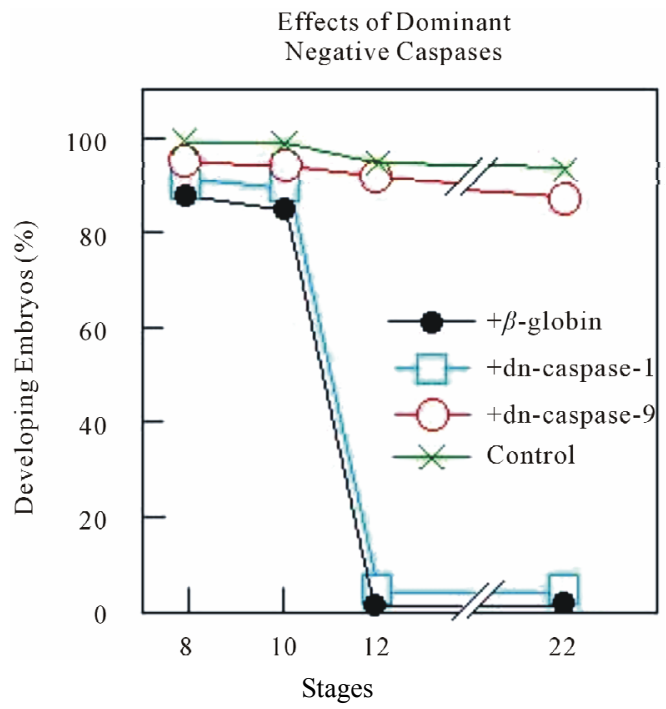

(b)

Figure 11. Inhibition of execution of SAMDC mRNAinjected apoptosis by peptide inhibitors or dominantnegative type caspase-9. Left: Different amounts of synthetic peptide inhibitor for caspase-9 (Ac-LEHD$\mathrm{CHO}$ ) (a) or caspase-1 (Ac-YVAD-CHO) (b) were co-injected with $100 \mathrm{pg} / \mathrm{egg}$ of SAMDC mRNA into Xenopus lavies fertilized eggs. Right: Effects of coinjection (each $1000 \mathrm{pg} / \mathrm{egg}$ ) of dominant-negative type mutant of caspase-9 (dnCaspase-9) or caspase-1 (dnCaspase-1) together with SAMDC mRNA. From Takayama et al. [71].

dominant-negative type caspase-1 [70]. We then generated "dominant-negative type" mutants (dn-caspases) of caspase-9 [69], in which the cysteine residue at the active site was replaced by phenylalanine, and we injected the mutated mRNA into fertilized eggs together with SAMDC mRNA [71]. We also generated here a dominant-negative type caspase- $1[69,72]$ by modifying the active site of wild type cDNAs $[73,74]$, and injected them into fertilized eggs together with SAMDC-mRNA [71]. We found here that dominant-negative type caspase-9 mRNA, but not dominant-negative type caspase-1 mRNA, suppressed SMDC-induced apoptosis (Figure 11, right). These results suggest that activation of caspase-9, but not caspase-1, is the key step for the execution of the apoptosis in SAMDC-mRNA injected embryos.

It is well known that caspases are provided as inactive procaspases and such precursor molecules of caspases (procapsases) are cleaved to give rise to active form [68]. We then tested if there appears the caspase-activating activity in the cytoplasm of the SAMDC mRNA-injected embryos before the execution of the apoptosis. We injected here SAMDC mRNA (200 pg/egg) into fertilized eggs, and prepared cell-free lysates from the injected embryos at stages 6.5 (still normally cleaving) and at 10.5 (already in the apoptotic process, and embryonic cells stop cleaving, but they were still not lyzed due to osmotic protection) (Figure 12(a)). On the other hand, we prepared ${ }^{35} \mathrm{~S}$-procaspases by in vitro-translation of mRNAs, and then incubated the radioactive procaspases in the embryo lysates. Analysis of the reaction products by gel electrophoresis revealed that the lysate of SAMDC-induced apoptotic embryos at stage at 10.5 , but not at stage 6.5 , cleaved ${ }^{35} \mathrm{~S}$-procaspase-9 into two peptides (Figure 12(b)). By contrast, both of the cell lysates of SAMDC-induced apoptotic embryos prepared at stage 6.5 embryos and stage 10.5 did not cleave ${ }^{35} \mathrm{~S}$-procaspase-1 (Figure 12(c)). These results suggested that in SAMDC mRNA-injected embryos, the activity to cleave procaspase-9 but not procaspase-1, appeared at postMBT stage. Based on these results, we concluded that caspase-9, but not caspase-1, is involved in the apoptosis executed at this very early stage.

\subsection{Maternal Nature of Caspase-9 in Xenopus Embryos}

We carried out Northern blot analysis using RNAs extracted from SAMDC mRNA-injected embryos and uninjected control embryos (Figure 13). In uninjected control embryos, we detected approximately 2.7 and $2.0 \mathrm{~kb}$ signals for caspase- 9 and caspase-1, respectively. mRNA for caspase- 9 occurred abundantly already in unfertilized eggs (stage 1) as a maternal mRNA. The level was maintained until the midblastula stage (stage 8), and started to decrease (at stage 10), reached the minimum level (at stage 12), then increased toward the late neurula stage (stage 22). This time-course of the changing level of caspase-9 mRNA was just as those observed with other maternal mRNAs such as aldolase A and C mRNAs [75]. On the other hand, mRNA for caspase-1 was detected 


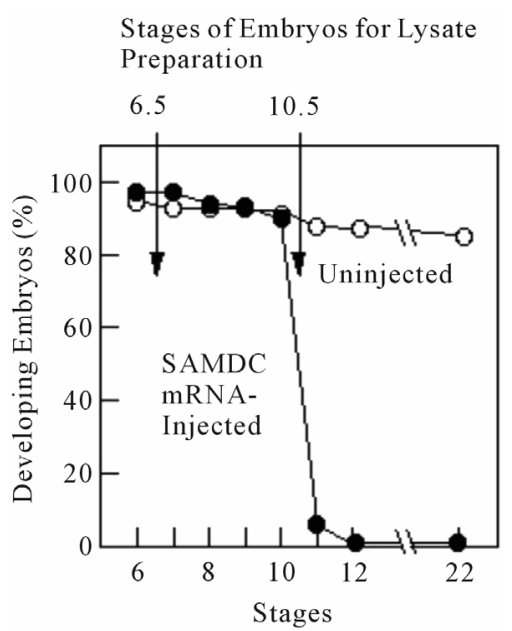

(a)

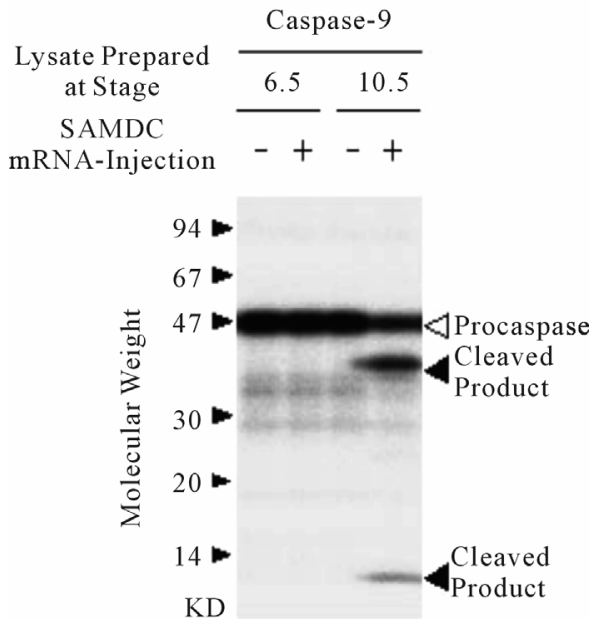

(b)

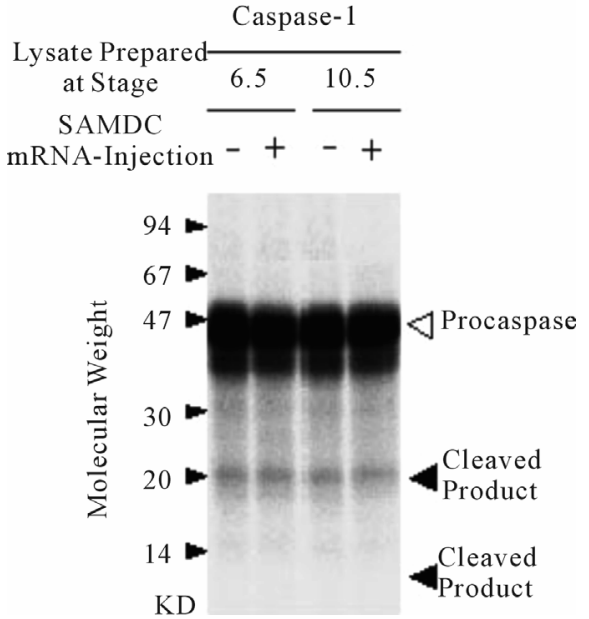

(c)

Figure 12. Induction of procaspase-9-cleaving activity in SAMDC mRNA-injected Xenopus embryos. (a) Embryos were injected with $100 \mathrm{pg} / \mathrm{egg}$ of SAMDC mRNA (closed circles) or beta-globin (open circles) into both of the blastmeres at the 2-cell stage (200 $\mathrm{pg} / \mathrm{embryo}$ ) and cultured in $1 \times$ Steinberg's solution. Cell-lysate was prepared at stage 6.5 or stage $10.5 .{ }^{35} \mathrm{~S}-$ labelled procaspase- 9 (b) and ${ }^{35}$ S-labelled procaspase-1 (c) were incubated with the cell lyzates prepared at stage 6.5 or 10.5 from embryos injected with either SAMDC mRNA $(+)$ or b-globin mRNA $(-)$. Reaction mixtures were subjected to gel electrophoresis under reducing conditions. From Takayama et al. [71].

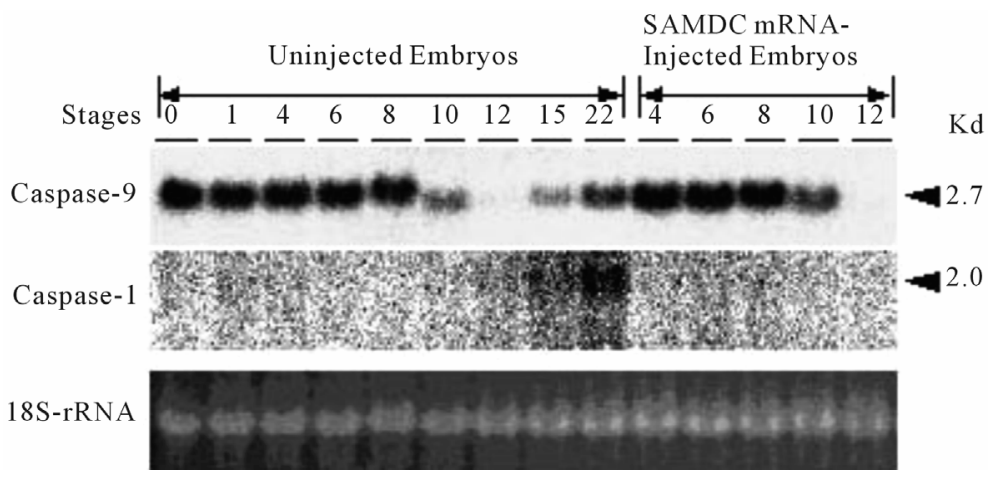

Figure 13. Northen blot analysis of caspase mRNAs in Xenopus embryos. Fertilized eggs were injected with SAMDC mRNA (100 pg/egg) or distilled water (uninjected control embryos) and cultured in $1 \times$ Steinberg's solution. RNAs isolated were subjected to Northern bot analysis with ${ }^{32} \mathrm{P}$-labelled probes specific for Xenopus caspase-9 or caspase-1. 18S rRNA wasstained as a loading marker with ethidium bromide. Experiments were not performed in SAMDC mRNA-injected embryos after stage 12 , because of the embryo death. From Takayama et al. [7].

only after embryos developed to the late gastrula stage (stage 12), and the level increased thereafter toward the late neurula stage (stage 22). Thus, caspase-1 mRNA is not a maternal mRNA and is activated only zygotically after the gastrula stage. The appearance of the mRNA for caspase-1 in post-gastrular embryos may be correlated to the fact that this enzyme is involved probably in programmed cell death in neural tissues [76]. These expression profiles of two mRNAs were not appreciably affected by SAMDC mRNA-injection throughout early stages (from stage 4 to stage 12).

In this series of experiments, we also analyzed the
mRNA for caspase-3, which is known to be activated by caspase-9 [68,69]. Caspase 3 mRNA $(1.6 \mathrm{~Kb})$ also occurred as a maternal mRNA, but the level was much lower as compared with that of caspase-9 throughout early stages. We then co-injected SAMDC mRNA (0.5 ng/egg) and a specific peptide inhibitor for caspase 3 (Z-D(OMe)GMD(OMe)FMK) (0.5 ng/egg) into Xenopus fertilized eggs. In this experiment, ca. $70 \%$ of the coinjected embryos did not undergo cell dissociation and developed beyond neurula stage (Kuroyanagi and Shiokawa, unpublished). We, therefore, assumed that caspase-3 is also involved as an executive caspase in the 
SAMDC-induced apoptosis, probably at a step downstream of caspase-9 [77,79].

We in vitro-transcribed mRNAs for caspase-9 or caspase- 1 and then performed experiments to inject different doses of these mRNAs into fertilized eggs. Injection of mRNAs of both caspase- 9 and caspase- 1 at $100 \mathrm{pg} / \mathrm{egg}$ induced cell dissociation shortly after MBT. We confirmed here that the DNAs extracted from the caspaseoverexpressed embryos formed DNA ladder for both caspase- 9 and caspase- 1 . When we injected these mRNAs together with Bcl-2 mRNA (100 pg/egg), we found that onset of cell dissociation was delayed for only $2-3 \mathrm{hr}$. Therefore, these caspases induce apoptosis when they are overexpressed in early embryos.

\subsection{Involvement of Caspase 8 in the SAMDC mRNA-Induced Apoptosis in Xenopus Embryos}

We extended our studies on the possible involvement of caspase-8. We first co-injected a synthetic peptide inhibitor for caspase-8 (Ac-IETD-CHO) and SAMDC mRNA into Xenopus fertilized eggs. We found here that the inhibitor of caspase-8 suppressed the SAMDC-induced apoptosis dosage-dependently [80]. We then prepared a dominant-negative type mutant of caspase- 8 , and injected it into fertilized eggs together with SAMDC mRNA. Here again, apoptosis executed by SAMDCoverexpression was suppressed. These results suggested that SAMDC induces apoptosis via steps that involve activation of caspase-8 [80].

We prepared lysates of SAMDC-overexpressed embryos at stage 6.5 (apoptosis is not yet executed) and at stage 10.5 (embryos are already apoptotic but are not lyzed because of the protection from the osmotic shock), and incubated the lysates with in vitro synthesized ${ }^{35} \mathrm{~S}-$ labelled procaspase- 8 . We found here that the lysate from SAMDC mRNA-injected embryos at the stage 10.5, but not stage 6.5 , cleaved procaspase- 8 [80], suggesting that procaspase- 8 is converted into active caspase- 8 in SAMDC-overexpressed embryos by the time of the execution of the apoptosis. We assume that the activation of caspase- 8 occurs prior to the activation of caspase- 9 as in other systems $[77,78]$.

\subsection{Comparison of SAMDC-Induced Apoptosis and p53-Induced Apoptosis}

p53 is a tumor suppressor protein and is highly expressed in Xenopus early embryos, and essential for normal development [81-84], yet its overexpression in Xenopus early embryos induces cell dissociation and developmental arrest at the gastrula stage [83]. We performed experiment to overexpress p53 mRNA in Xenopus embryos, and compared the effects of the overexpression of p53 with that of SAMDC on Xenopus development. For this purpose, we injected different amounts $(10,100$, and $1000 \mathrm{pg} / \mathrm{egg}$ ) of mRNAs for SAMDC, caspase-8, p53, beta-galactosidase, caspase- 9 , and alpha-globin into Xenopus fertilized eggs and examined the development of the injected embryos. As in embryos injected with mRNAs for SAMDC and caspase-9, cell dissociation took place in embryos injected with mRNA for caspase-8 and p53 at the early gastrula stage, although injection of mRNA for beta-galactosidase and alpha-globin did not induce such effects even at $1000 \mathrm{pg} / \mathrm{egg}$. The apoptosisinducing effects were dosage-dependent for both caspase- 8 mRNA and p53 mRNA. DNAs extracted from embryos injected with mRNA for caspase-8, p53 or SAMDC were all found to form DNA ladder in their fast-moving regions, whereas DNA from embryos injected with alpha-globin mRNA migrated as high-molecular-weight DNA at the top of the gel. When we injected mRNA of an anti-apoptotic factor, Bcl-2 [56,57], together with mRNA for $\mathrm{p} 53$ or caspase- 8 , cell dissociation was delayed by about 3 hours but all the embryos died after the $3 \mathrm{hr}$. We then concluded that injection of caspase- 8 or p 53 mRNA induces cell dissociation due to the execution of apoptosis.

$\mathrm{Xdm}-2$, a Xenopus homologue of mouse Mdm-2, which directly binds p53 and inhibits p53-mediated transactivation [85], is expressed in early Xenopus embryos, and is important for the control of p53 activities [86]. When we injected mRNA for Xdm-2 together with mRNA for either p53 or SAMDC into Xenopus fertilized eggs, p53-induced apoptosis, but not SAMDC-induced apoptosis, was suppressed. Also, these results suggest that SAMDC-induced apoptosis is not executed through the p53-mediated pathway. We then tested effects of co-injection of a synthetic peptide-inhibitor for caspase-9 (Ac-LEHD-CHO) and caspase-1 (Ac-YVAD-CHO) on the apoptosis to be executed by overexpression of p53 mRNA and SAMDC mRNA. The peptide inhibitor for caspase-9 inhibited both p53-induced and SAMDC-induced apoptosis, whereas the peptide inhibitor for caspase-1 did not show such effects. We further tested effects of co-injection of dominant-negative type caspase-9 mRNA and dominant-negative type caspase-1 mRNA [69] on the apoptosis-inducing effects of SAMDC mRNA and p53 mRNA. Dominant-negative type caspase-9 suppressed both p53-induced and SAMDC-induced apoptosis, whereas dominant-negative type caspase-1 did not show such effects. These results indicated that both SAMDC and p53 execute apoptosis through the activity of caspase-9, but not through the activity of caspase-1.

We then injected a peptide-inhibitor for caspase-8 (Ac-IETD-CHO) or caspase-1 (Ac-YVAD-CHO) together with mRNA for p53 or SAMDC into fertilized 
eggs. Both the peptide inhibitors for caspase- 8 and caspase-1 did not inhibit the p53-induced apoptosis, whereas the peptide inhibitor for caspase-8, but not caspase-1, inhibited the SAMDC-induced apoptosis (Figure 14). In this case, SAMDC-overexpressed embryos rescued by the co-injection of the peptide inhibitor developed beyond the neurula stage (stage 22). We also found that dominant-negative type caspase- $8 \mathrm{mRNA}$ did not suppress p53-induced apoptosis, although it suppressed the execution of SAMDC-induced apoptosis. These results suggest that while p53 induces apoptosis without passing the step that involves caspase-8, SAMDC-induced apoptosis is mediated through the step that involves caspase- 8 .

\subsection{In p53 mRNA-Induced Apoptotic Embryos Activity to Process Procaspase-8 Does Not Appear}

We injected either p53 mRNA or SAMDC mRNA into Xenopus fertilized eggs, and after culturing the injected

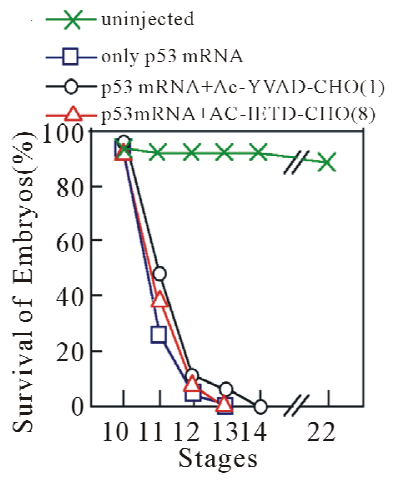

(a)

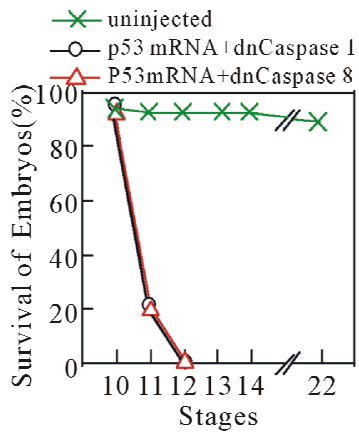

(c)

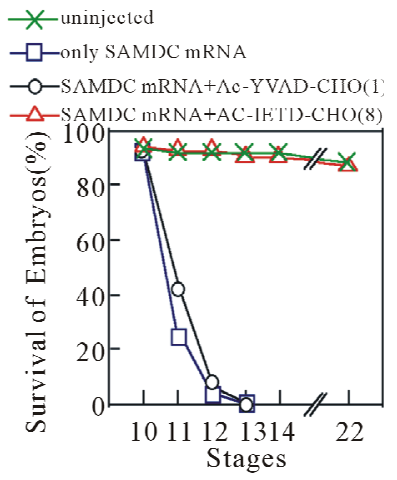

(b)

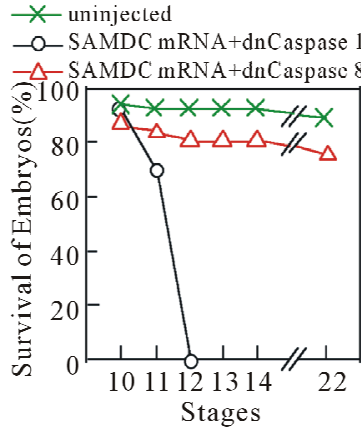

(d)
Figure 14. Effects of coinjection of peptide inhibitors and dominant-negative type mutants of caspase- 8 and caspase-1 into p53 or SAMDC mRNA-injected embryos. Fertilized eggs were co-injected with 1000 pmoles of peptide-inhibitor for caspase- 8 or caspase- 1 together with mRNA for p53 (a) or SAMDC (b). Also, fertilized eggs were co-injected with 1000 pg/egg of mRNA for dominant-negative type mutant of caspase-8 (dnCaspase-8) or caspase-1 (dnCaspase-1) together with mRNA for p53 (c) or SAMDC (d). From Shiokawa et al. [80]. embryos in $1 \times$ Steinberg' solution, prepared their lysates at stages 6.5 (still normally cleaving) and 10.5 (already in the apoptotic process). We incubated ${ }^{35} \mathrm{~S}$-labelled procaspase- 8 in the embryo lysate, and analyzed the reaction products by gel electrophoresis. It was found here that while the lysate from p53 mRNA-induced apoptotic embryos cleaved procaspase-9, it does not cleave procaspase-8, inspite of the fact that the lysate of SAMDC mRNA-injected apoptotic embryos cleaved both procaspase- 9 and procaspase- 8 (Figure 15). It is then concluded that in p53 mRNA-injected embryos the activity to cleave procaspase-9, but not procaspase-8, appears, although in SAMDC mRNA-injected embryos, activities to cleave both procaspase- 8 and -9 appear before the execution of apoptosis.

\subsection{Caspase-8 mRNA Is Newly Synthesized in SAMDC-Overexpressed Cleavage Stage Embryos}

Since caspase- 8 appeared to be involved in the SAMDCinduced apoptosis, we injected mRNA of either p53 or SAMDC into fertilized eggs and analyzed the RNAs extracted from embryos at stage 6.5 (pre-MBT stage) or 8.5 (MBT stage). Northern blot analyses revealed that caspase- 8 mRNA does not occur as a maternal mRNA in the untreated control embryos (Figure 16). To our surprise, however, the caspase- 8 mRNA $(3.0 \mathrm{~Kb})$ appeared in SAMDC mRNA-injected embryos both at non-apoptotic (stage 6.5) and apoptotic (stage 8.5) stages [8]. In p53 mRNA-injected embryos, caspase- 8 mRNA was not detected at both stages, although caspase- 9 mRNA was detected throughout stages. The level of caspase- 9 mRNA was not significantly affected by p53 mRNA injection at both stages. By RT-PCR analysis we obtained the parallel results (Figure 17).

These results indicate that caspase- 8 mRNA was detected as early as at stage 6.5. For many years, most Xenopus researchers believed that pre-MBT embryos are transcriptionally totally silent. It is true that rRNA synthesis is absent during pre-MBT stage until it starts right after MBT [30,31]. However, several RNAs have been reported to be synthesized during the pre-MBT stage. Such RNAs include heterogeneous mRNA-like RNA labeled with $3 \mathrm{H}$-uridine [21], and RNAs of nodal-related TGF-beta superfamily member genes, Xnr5 and Xnr6 [24]. Thus, caspase- 8 mRNA is the third species of polymerase II-transcribed RNA that has been reported to be expressed in pre-MBT stage. It is worth pointing out here that the activity to cleave pro-caspase- 8 was detected only at stage 10.5 but not 6.5 . We, therefore, suggest that while transcription of caspase- 8 is activated at stage 6.5 , a factor that converts procaspase- 8 to active caspase- 8 is induced at stages later than stage 6.5. 


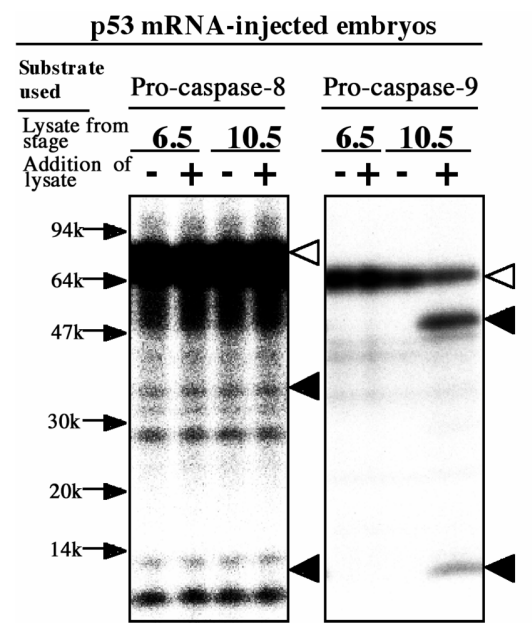

(a)

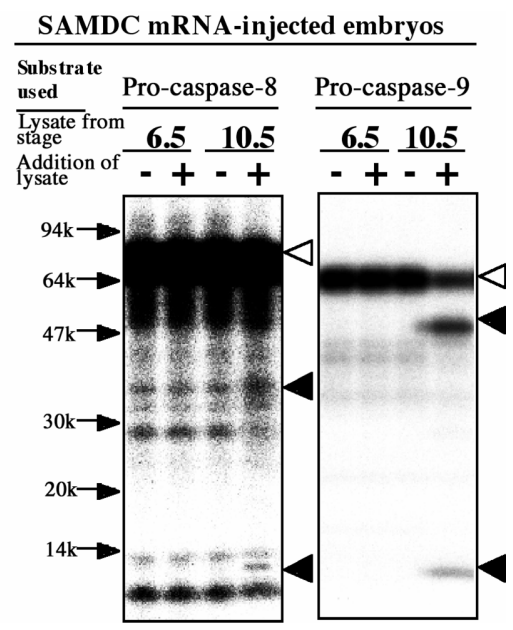

(b)

Figure 15. Appearance of the activity to cleave pro-caspase- 8 and procaspase- 9 in the lysates of p53 mRNA- and SAMDC mRNA-overexpressed apoptotic embryos. ${ }^{35}$ S-methionine-labelled enzymatically-defective pro-caspases were prepared and incubated with lysates prepared from embryos injected with mRNA (+) (1000 $\mathrm{pg}$ /embryo) for p53 or SAMDC. Lysates were also prepared from embryos injected with beta-globin mRNA alone $(-)(1000 \mathrm{pg} / \mathrm{embryo})$ as control experiments Reaction products were analyzed on SDS-PAGE under the reducing condition and autoradiographed. (a) Lysate of p53-overexpressed embryos. (b) Lysate of SAMDC-overexpressed embryos. Molecular size markers, locations of pro-caspase (open arrow head), and cleaved products (closed arrow heads) are shown. From Shiokawa et al. [80].

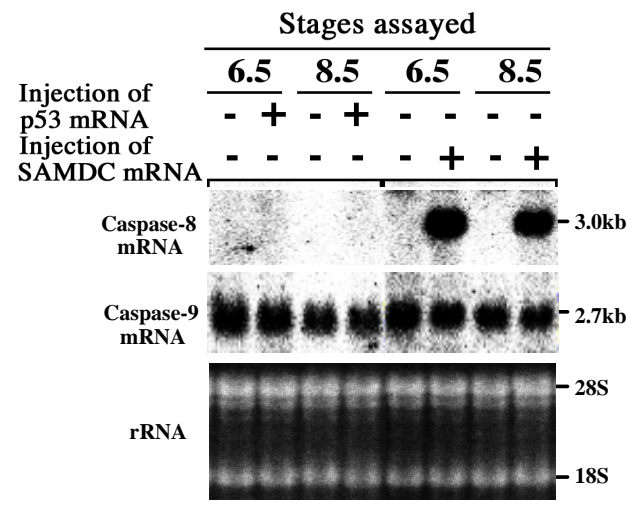

Figure 16. Northern blot analyses for caspase-8 and caspase-9 mRNAs in p53- or SAMDC-overexpressed embryos. Fertilized eggs were injected $(+)$, or not $(-)$ injected, with p53 or SAMDC mRNA (1000 pg/embryo) and cultured in $1 \times$ Steinberg's solution. RNAs were isolated from embryos at different stages. (A) RNAs were separated on a $1 \%$ agarose gel containing formaldehyde, transferred to a nylon membrane, and hybridized with ${ }^{32} \mathrm{P}$-labelled DNA probes for Xenopus caspase-8 and 9. From Shiokawa et al. [80].

\subsection{A Possible Correlation between SAMDC-Induced Apoptosis and a High Activity of mRNA Cap Methylation in pre-MBT Stage}

SAMDC overexpression depletes SAM from cells [7],

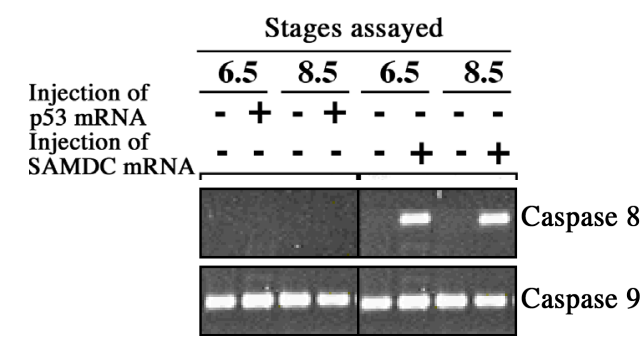

Figure 17. RT-PCR analyses for caspase- 8 and caspase-9 mRNAs in p53- or SAMDC-overexpressed embryos. RNA analyzed in the experiment in Fig. 18 was subjected to RT-PCR. The signal obtained for caspase- 8 mRNA was $396 \mathrm{bp}$, and that for caspase-9 mRNA was 539bp. 28S and $18 \mathrm{~S}$ rRNAs were stained with ethidium bromide. From Shiokawa et al., [80].

and this might cause the inhibition of mRNA cap methyllation, which may in turn induce the inhibition of protein synthesis [7]. In our early experiment to label Xenopus embryonic cells with (methyl- ${ }^{3} \mathrm{H}$ )methionine at cleavage, blastula, gastrula, and neurula stages, a very high activity was detected in mRNA cap methylation in cleavage stage embryos [30] (Figure 18). At this stage there is no ribosomal RNA synthesis as detected by almost negligible 2'-O-methylation in high-molecular-weight RNA species [30,31]. It may be assumed that SAMDC overexpression suppresses this active mRNA cap methylation. 


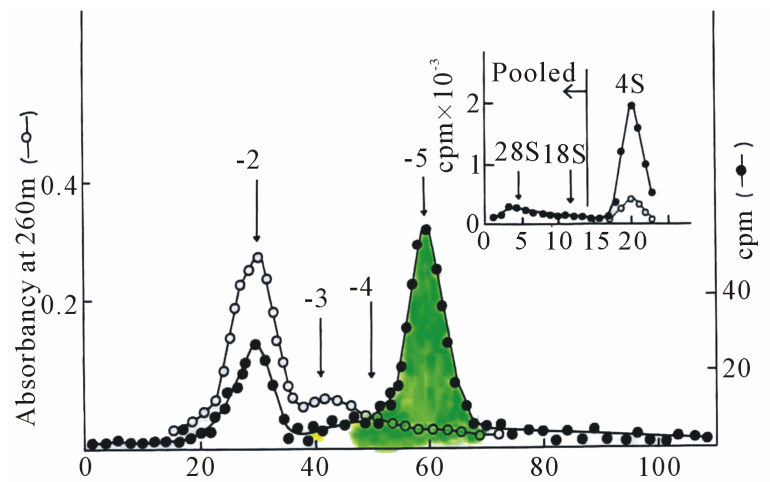

(a)

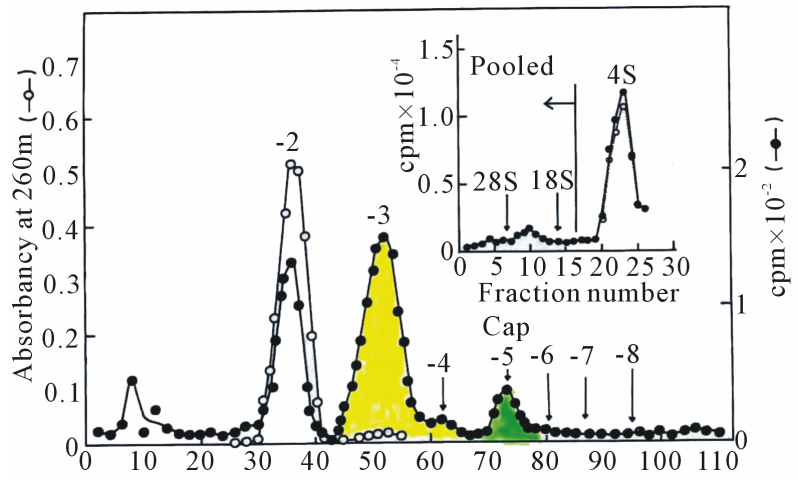

(b)

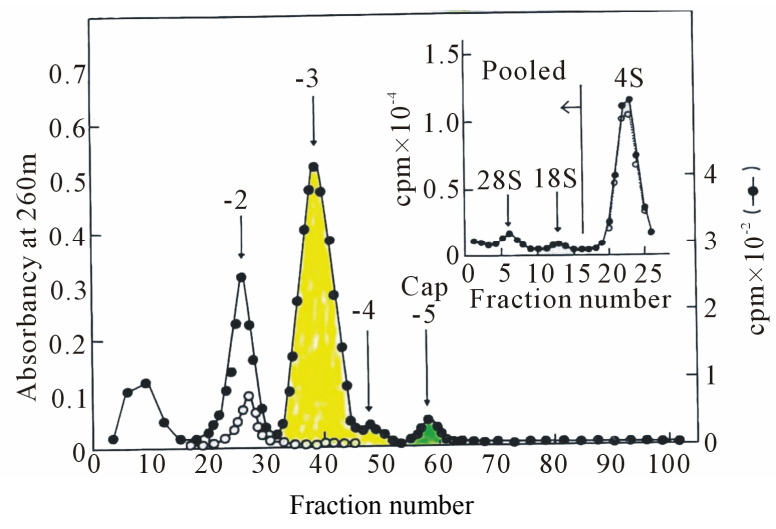

(c)

Figure 18. Sucrose density gradient profiles of (methyl- ${ }^{3} \mathrm{H}$ ) methionine-labeled RNA and DEAE-Sephadex A25 chromatographic profiles of nuclease digests of the high-molecular weight RNA fractions recovered from sucrose density gradients. Embryos were dissociated and their cells were labeled with (methyl- ${ }^{3} \mathrm{H}$ )methionine. Numbers indicated are positions of marker oligonucleotides of the indicated charge values. The number of embryos used were 3000 morulae (a), 300 early blastulae (b), 50 gastrulae (c) in order to obtain RNA from ca. $10^{6}$ cells at all the stages. In (a), experiments were carried out using 300 morulae at a time and the whole procedure was performed with 10 separate samples and nuclease digests obtained were pooled and used at a time. Two yellow components $(-3$ and -4 components) are for $\mathrm{N}_{\mathrm{p}}^{\mathrm{m}} \mathrm{N}_{\mathrm{p}}$ and $\mathrm{N}_{\mathrm{p}}^{\mathrm{m}} \mathrm{N}_{\mathrm{p}}^{\mathrm{m}} \mathrm{N}_{\mathrm{p}}$, both derived only from rRNA and the green peak ( -5 component) is for type I cap structure $\left(\mathrm{m}_{7} \mathrm{G}_{\mathrm{ppp}} \mathrm{N}_{\mathrm{p}}^{\mathrm{m}} \mathrm{N}_{\mathrm{p}}\right)$. From Shiokawa et al. [30].
In this connection, we co-injected SAMDC mRNA and cap analogue $\left(\mathrm{m}^{7} \mathrm{GpppG}\right)$ into Xenopus fertilized eggs. We found here that ca. $50 \%$ of the co-injected embryos were rescued from SAMDC-induced apoptotic arrest and developed into tadpoles. By contrast, the apoptosis executed by p53 overexpression was not suppressed by the cap analogue [87] (Figure 19). Therefore, the exogenously-added cap analog might have rescued the SAMDC-induced inhibition of protein synthesis by supplying the methylated CAP analogue.

\section{CONCLUSION}

Xenopus embros have unique polyamine composition. From the studies of the polyamine metabolism, we cloned cDNA of SAMDC, one of the key enzyme in the polyamine regulation, and then the present series of experiments started when we overexpressed the in vitorotranscribed SAMDC mRNA in Xenopus fertilized eggs. In SAMDC-overexpressed embryos, SAM, a substrate of SAMDC, was exhausted, and protein synthesis was greatly inhibited, and at midblastula stage, or MBT, SAMDC-overexpressed embryos suddenly underwent massive cell dissociation and died, although they developed quite normally up to early blastula stage. The SAMDC-induced cell dissociation turned out to be due to apoptosis, and the caspase-9 which seems to be a key caspase in this system was found to exist in the egg cytoplasm from the beginning as a maternal mRNA. Thus, we came across quite unexpectedly the phenomenon of the execution of the maternal program of apoptosis. This apoptosis was completely suppressed by co-injection of Bcl-2 mRNA, EGBG, an inhibitor of SAMDC, or SAM, and rescued embryos developed beyond tadpole stage. We microinjected SAMDC mRNA into only one blastomere at 8- to 32-cell stage embryos, and after analyzing the behavior of its descendant cells, reached a conclusion that the apoptosis which is executed so early in the development is a kind of "fail-safe" mechanism to check and eliminate damaged cells before they enter the morphogenic phase which comes after the MBT stage. In SAMDC-overexpressed embryos, it appeared that caspase-8 is also involved. Interestingly, de novo synthesis of caspase- 8 mRNA takes place at cleavage stage and it appeared that the activation of caspase- 8 is followed by activation of caspase-9. Caspase- 8 mRNA is not a maternal mRNA, but is newly synthesized during cleavage stage (pre-MBT stage) as a result of the overexpression of SAMDC, but not of p53. Based on the results, we conclude that Xenopus embryos have at least two pathways to execute the maternal program of apoptosis; one executed by SAMDC-overexpression, and the other executed by $\mathrm{p} 53$-overexpression, and while the former is executed through activation of caspase- 8 before the activation of caspase- 9 , the latter is activated not through 

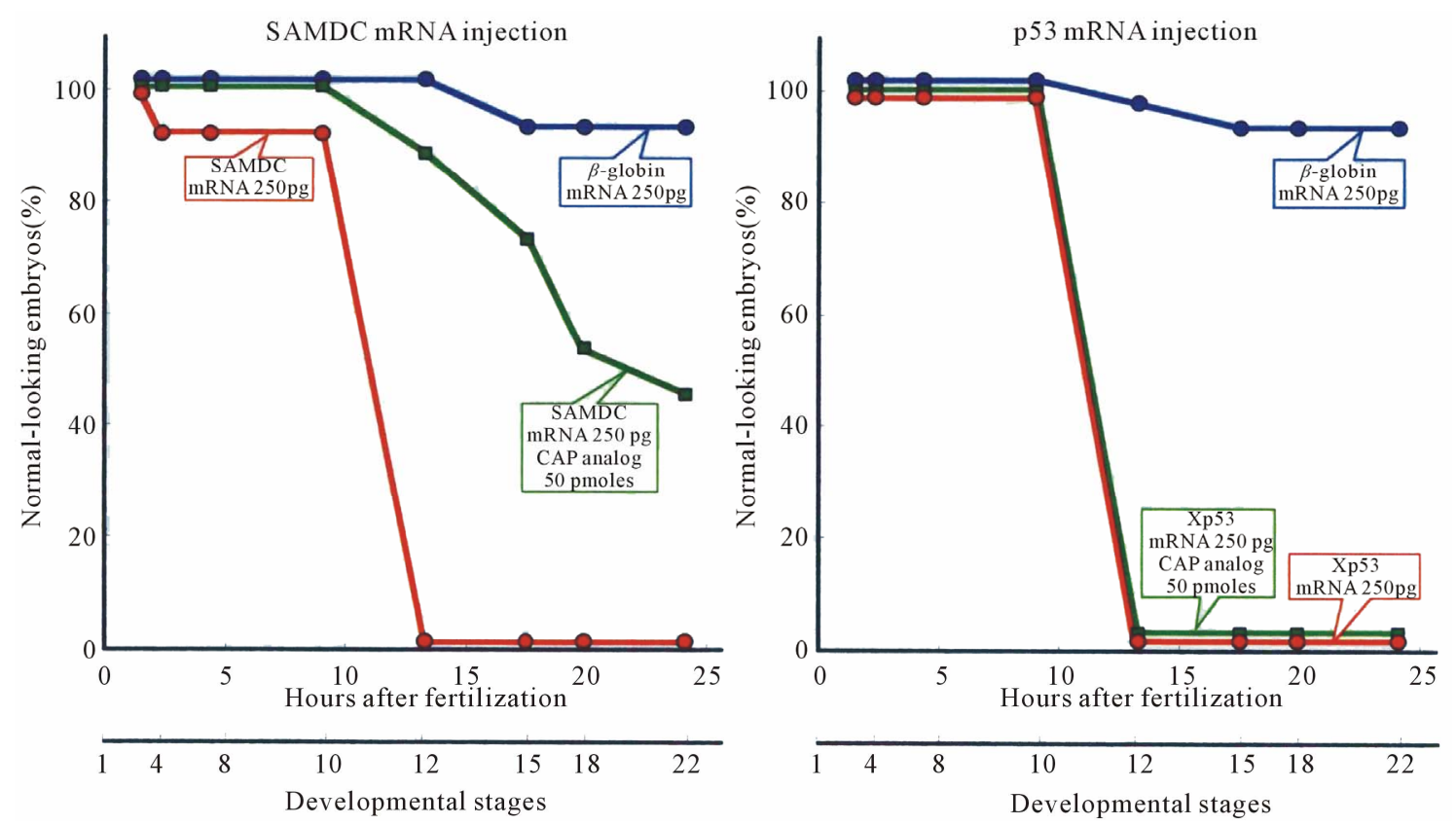

Figure 19. Partial rescue of embryos from SAMDC mRNA-induced, but not p53 mRNA-induced, apoptosis by co-injection of a cap analogue. Embryos were co-injected with either SAMDC mRNA and cap analogue or p53 mRNA and cap analogue as indicated in the figures, and percentage of normal developing embryos were plotted. From Shiokawa et al. [87].

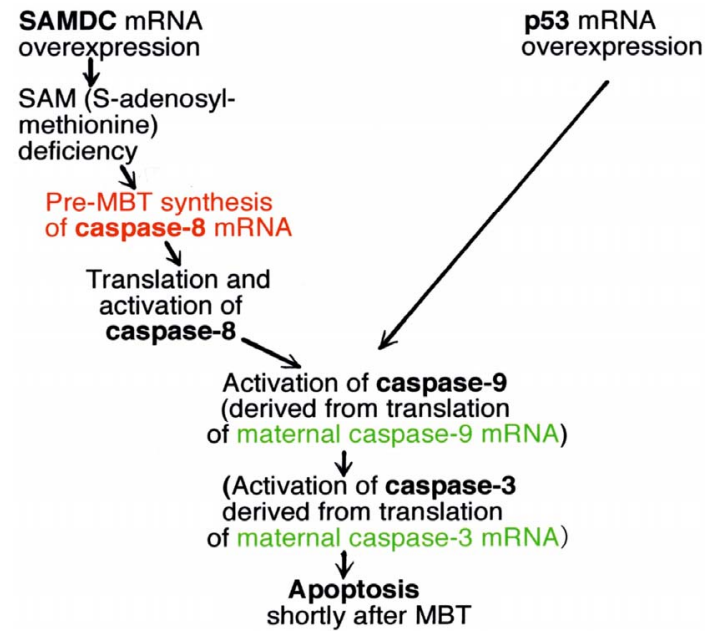

Figure 20. A model which shows sequence of events in activetion of apoptosis in SAMDC- and p53-overexpressed Xenopus embryos. From Shiokawa et al. [88].

caspase-8 but directly through caspase-9 [88] (Figure 20). We assume that further experiment to clarify the control mechanism of these unique apoptotic systems in Xenopus early embryos would provide important insights not only for the studies of apoptosis itself but also for the elucidation of the developmental control mechanism.

\section{REFERENCES}

[1] Nieuwkoop, P.D. and Faber, J. (1967) Normal Table of
Xenopus laevis (Daudin). North Holland, Amsterdam.

[2] Estabel, J., Koenig, N., Shiokawa, K. and Exbrayat, J.-M. (2005) Apoptosis, research signpost. In: Scovassi, A.I. Ed., Kerala, 145-167.

[3] Glucksman, A. (1951) Cell deaths in normal vertebrate ontogeny. Biological Review, 26, 59-86. doi:10.1111/j.1469-185X.1951.tb00774.x

[4] Imoh, H. (1986) Cell death during normal gastrulation in the newt, Cynops pyrrhogaster. Cell Differentiation, 19, 35-42. doi:10.1016/0045-6039(86)90023-0

[5] Sible, J.C., Anderson, J.A., Lewelly, A.L. and Maller, J. L. (1997) Zygotic transcription is required to block a maternal program of apoptosis in Xenopus embryos. Developmental Biology, 189, 335-346. doi:10.1006/dbio.1997.8683

[6] Hensey, C. and Gautier, J. (1997) A developmental timer that regulates apoptosis at the onset of gastrulation. Mechanism of Development, 69, 183-195. doi:10.1016/S0925-4773(97)00191-3

[7] Shibata, M., Shing, J., Yasuhiko, Y., Kai, M., Miura, K., Shimogori, T., Kashiwagi, K., Igarashi, K. and Shiokawa, K. (1998) Overexpression of S-adenosylmethionine decarboxylase (SAMDC) in early Xenopus embryos induces cell dissociation and inhibits transition from the blastula to gastrula stage. International Journal of Developmental Biology, 42, 675-686.

[8] Hensey, C. and Gautier, J. (1998) Programmed cell death during Xenopus development: A spatial-temporal analysis. Developmental Biology, 203, 36-48. doi:10.1006/dbio.1998.9028

[9] Kai, M., Higo, T., Yokoska, J., Kaito, C., Kajita, E., Fu- 
kamachi, H., Takayama, E., Igarashi, K. and Shiokawa, K. (2000) Overexpression of $S$-adenosylmethionine decarboxylase (SAMDC) activates the maternal program of apoptosis shortly after MBT in Xenopus embryos. Internationa Journal of Developmental Biology, 44, 507-510.

[10] Hensey, C. and Gautier, J. (1999) Developmental regulation of induced and programmed cell death in Xenopus embryos. Annals of the New York Academy of Sciences, 887, 105-119. doi:10.1111/j.1749-6632.1999.tb07926.x

[11] Finkielstein, C.V., Lewellyn, A.L. and Maller, J.L. (2001) The midblastula transition in Xenipus embryos activates nultiple pathways to prevent apoptosis in response to DNA damage. Proceedings of National Academy of Science of USA, 98, 1006-1011. doi:10.1073/pnas.98.3.1006

[12] Anderson, J.A., Lewellyn, A.L., and Maller, J.L. (1997) Ionizing radiation induces apoptosis and elevates cyclin A1-Cdk2 activity before but not after the midblastula transition in Xenopus. Molecular Biology of Cell, 8, 1195-1206.

[13] Tribulo, C., Aybar, M. Sanchez, S.S. and Mayor, R. (2004) A balance between the anti-apoptotic activity of Slug and the apoptotic activity of $m s x l$ is required for the proper development of the neural crest. Developmental Biology, 275, 325-342. doi:10.1016/j.ydbio.2004.07.041

[14] Shinga, J., Itoh, M., Shiokawa, K., Taira, S. and Taira, M. (2001) Early patterning of the prospective midbrainhinfdbrain boundary by the HES-related gene XHR1 in Xenopus embryos. Mechanisms of Development, 109, 225-239. doi:10.1016/S0925-4773(01)00528-7

[15] Estabel, J., Mercer. A., König, N. and Exbrayat, J.-M. (2003) Programmed cell death in Xenopus laevis spinal cord, tail and other tissues, prior to, and during, metamorphosis. Life Science, 73, 3297-3306.

doi:10.1016/j.lfs.2003.06.015

[16] Rowe, I., Coen, L., Le Blay, K., Le Mével, S. and Demeneix, B. (2002) Autonomous regulation of muscle fibre fate during metamorphosis in Xenopus tropicalis. Developmental Dynnamics, 224, 381-390. doi:10.1002/dvdy.10117

[17] Shi, Y.-B. and Brown, D.D. (1993) The earliest changes in gene expression in tadpole intestine induced by thyroid hormone. Journal of Biological Chemistry, 268, 2031220317.

[18] Das, B., Schreider, A.M., Huang, H. and Brown, D.D. (2002) Multiple thyroid hormone-induced muscle growth and death programs during metamorphosis in Xenopus laevis. Proceedings of National Academy of Science of USA, 99, 12230-12235. doi:10.1073/pnas.182430599

[19] Signoret, J. and Lefresne, J. (1973) Contribution à l'étude de la segmentation de l'oeuf d'axolotl. II. Influence de modifications du noyau et du cytoplasme sur les modalités de la segmentation. Annuals of Embryology and Morphology, 6, 299-307.

[20] Newport, J. and Kirschner, M. (1982) A major developmental transition in early Xenopus embryos: I. Characterization and timing of cellular changes at the midblastula stage. Cell, 30, 675-686. doi:10.1016/0092-8674(82)90272-0

[21] Nakakura, N., Miura, T., Yamana, K., Ito, A. and Shio- kawa, K. (1987). Synthesis of heterogeneous mRNA-like RNA and low-molecular-weight RNA before the midblastula transition in embryos of Xenopus laevis. Developmental Biology, 123, 421-429. doi:10.1016/0012-1606(87)90400-3

[22] Shiokawa, K., Kurashima, R. and Shinga, J. (1994) Temporal control of gene expression from endogenous and exogenously-introduced DNAs in early embryogenesis of Xenopus laevis. International Journal of Developmental Biology, 38, 249-255.

[23] Shiokawa, K., Misumi, Y. Tashiro, K. and Yaman, K. (1989) Changes in the patterns of RNA synthesis in early embryogenesis of Xenopus laevis. Cell Differentiaion, 28, 17-25. doi:10.1016/0922-3371(89)90019-1

[24] Yang, J., Tan, C., Darken, R.S., Wilson, P.A. and Klein P.S. (2002) $\beta$-Catenin/Tcf regulated transcription prior to the midblastula transition. Development, 129, 5743-5752. doi: $10.1242 /$ dev.00150

[25] Heasman, J. (2006) Patterning the early Xenopus embryo. Development, 133, 1205-1217. doi:10.1242/dev.02304

[26] Graham, C.F. and Morgan, R.W. (1966) Changes in the cell cycle during early amphibian development. Developmental Biology, 14, 439-460. doi:10.1016/0012-1606(66)90024-8

[27] Minoura, I., Nakamura, H., Tashiro, K. and Shiokawa, K. (1995) Stimulation of circus movement by activin, bFGF and TGF-beta 2 in isolated animal cap cells of Xenopus laevis. Mechanism of Development, 49, 65-69. doi:10.1016/0925-4773(94)00303-5

[28] Carter, A.D. and Sible, J.C. (2003). Loss of XChk1 function triggers apoptosis after the midblastula transition in Xenopus embryos. Mechanism of Development, 120, 315 323. doi:10.1016/S0925-4773(02)00443-4

[29] Wroble, B.N. and Sible, J.C. (2005) Chk2/Cds1 protein kinase blocks apoptosis during early development of Xenopus laevis. Developmental Dynamics, 233, 13591365. doi:10.1002/dvdy.20449

[30] Shiokawa, K., Misumi, Y. and Yamana, K. (1981) Demonstration of rRNA synthesis in pre-gastrular embryos of Xenopus laevis. Development Growth and Differentiation, 23, 579-587. doi:10.1111/j.1440-169X.1981.00579.x

[31] Shiokawa, K., Tashiro, K., Misumi, Y. and Yamana, K. (1981) Non-coordinated synthesis of RNA's in pre-gastrular embryos of Xenopus laevis. Development, Growth and Differentiation, 23, 589-597. doi:10.1111/j.1440-169X.1981.00589.x

[32] Nakahashi, T. and Yamana, K. (1976) Biochemical and cytological examination of the initiation of ribosomal RNA synthesis during gastrulation of Xenopus laevis. Development, Growth and Differentiation, 18, 329-339. doi:10.1111/j.1440-169X.1976.00329.X

[33] Shiokawa, K., Yamana, K., Fu, Y., Atsuchi, Y. and Hosokawa, K. (1990) Expression of exogenously introduced bacterial chloramphenicol acetyltransferase gene in Xenopus laevis embryos before the midblastula transition. Roux's Archive of Developmental Biology, 198, 322-329. doi:10.1007/BF00383770

[34] Etkin, L.D. and Balcells, S. (1985) Transformed Xenopus 
embryos as a transient expression system to analyze gene expression at the midblastula transition. Developmental Biology, 108, 173-178. doi:10.1016/0012-1606(85)90019-3

[35] Kappas, N.C., Savage, P., Chen, K.C., Walls, A.T. and Sible, J.C. (2000) Dissection of the XCHk1 signaling pathway in Xenopus laevis embryos. Molecular Biology of the Cell, 11, 3101-3108.

[36] Petrus, M.J., Wilhem, D.E., Murakami, M., Kappas, M.C., Carter, A.D., Wroble, B.N. and Sible, J.C. (2004) Altered expression of Chk1 disrupts cell cycle remnodeling at the midblastula transition in Xenopus laevis embryos. Cell Cycle, 3, 212-217. doi:10.4161/cc.3.2.647

[37] Taber, C.W. and Taber, H. (1984) Polyamines. Annual Review of Biochemistry, 53, 749-790. doi:10.1146/annurev.bi.53.070184.003533

[38] Pegg, A.E. (1986) Recent advances in the biochemistry of polyamines in eukaryotes. Biochemical Journal, 234, 249-262.

[39] Davis, R.H., Morris, D.R. and Coffino, P. (1992) Sequestered end products and enzyme regulation: The case of ornithine decarboxylase. Microbiological Review, 56, 280-290.

[40] Guirard, B.M. and Snell, E.E. (1964) Effect of polyamine structure on growth stimulation and spermine and spermidine content of lactic acid bacteria. Journal of Bacteriology, 88, 72-80. doi:10.1126/science.6768132

[41] Fozard, J.R., Part, M., Prakash, N.J., Grove, J., Schechter, P.J., Sjoerdsma, A. and Koch-Weser, J. (1980) L-Ornithine decarboxylase: An essential role in early mammalian embryogenesis. Science, 208, 505-508.

[42] Loewkvist, B., Emanuelsson, H. and Heby, O. (1985) Changes in polyamine synthesis and concentrations during chick embryo development. Journal of Experimental Zoology, 234, 375-382. doi:10.1002/jez.1402340307

[43] Kusunoki, S. and Yasumasu, I. (1978) Inhibitory effect of alpha-hydrazinoornithine on egg cleavage in sea urchin eggs. Developmental Biology, 67, 336-345. doi:10.1016/0012-1606(78)90204-X

[44] Emanuelsson, H. and Heby, O. (1978) Inhibition of putrescine synthesis blocks development of the polychete Ophryotrocha labronica at gastrulation. Proceedings of National Academy of Science of USA, 75, 1039-1042. doi:10.1073/pnas.75.2.1039

[45] Dion, A.S. and Herbst, E.J. (1970) Polyamine changes during development of Drosophila melanogaster. Annual of New York Academy of Science, 171, 723-734. doi:10.1111/j.1749-6632.1970.tb39384.x

[46] Osborne, H.B., Mulner-Lorillon, O., Marot, J. and Belle, R. (1989) Polyamine levels during Xenopus laevis oogenesis: A role in oocyte competence to meiotic resumption. Biochemical and Biophysical Research Communications, 158, 520-526. doi:10.1016/S0006-291X(89)80080-4

[47] Shinga, J., Kashiwagi, K., Toshiro, K., Igarashi, K. and Shiokawa, K. (1996) Maternal and zygotic expression of mRNA for $S$-adenosylmethionine decarboxylase and its relevance to the unique polyamine composition in Xeno- pus oocytes and embryos. Biochimica et Biophysica Acta, 1308, 31-40. doi:10.1016/0167-4781(96)00020-6

[48] Sunkara, P.S., Wright, D.A. and Nishioka, K. (1981) An essential role for putrescine biosynthesis during meiotic maturation of amphibian oocytrd. Developmental Biology, 87, 351-355. doi:10.1016/0012-1606(81)90158-5

[49] Younglai, E.V., Godeau, F., Mester, J. and Baulieu, E.E. (1980) Increased ornithine decarboxylase activity during meiotic maturation in Xenopus laevis oocytes. Biochemical and Biophysical Research Communications, 96, 12741281. doi:10.1016/0006-291X(80)90089-3

[50] Osborne, H.B., Duval, C., Ghoda, L., Omilli, F., Bassez, T. and Coffino, P. (1991) Expression and post-ytanslational regulation of ornithine decarboxylase during early Xenopus development. European Journal of Biochemistry, 202, 575-581. doi:10.1111/j.1432-1033.1991.tb16410.x

[51] Osborne, H.B., Cormier, P., Lorillon, O., Maniey, D. and Belle, R. (1993) Anappraisal of the devekiomental importance of polyamine changes in early Xenopus embryos. International Journal of Developmental Biology, 37, 615618.

[52] Rosander, U., Holm, I., Grahn, B., Lovtrup-Rein, H., Mattsson, M. and Heby, O. (1995) Down-regulation of ornithine decarboxylase by an increased degradation of the enzyme during gastrulation of Xenopus laevis. Biochimica et Biophysica Acta, 1264, 121-128. doi:10.1016/0167-4781(95)00136-5

[53] Russell, D.H. (1971) Putrescine and spermidine biosynthesis in the development of normal and anucleokate mutants of Xenopus laevis. Proceedings of National Academy of Science of USA, 68, 523-527.

[54] Heby, O. and Persson, L. (1990) Molecular genetics of polyamine synthesis in eukaryotic cells. Trends in Biochemical Science, 15, 153-158. doi:10.1016/0968-0004(90)90216-X

[55] Suzuki, T., Sadakata, Y., Kashiwagi, K., Hoshino, K., Kakinuma, Y., Shirahata, A. and Igarashi, K. (1993) Overproduction of S-adenosylmethionine decarboxylase in ethylglyoxal-bis(guanylhydrazone)-resistant mouse FM3A cells. European Journal of Biochemistry, 215, 247-253. doi:10.1111/j.1432-1033.1993.tb18029.X

[56] Yang, J., Liu, X., Bhalla, K., Kim, C.N., Ibrado, A.M., Cai, J., Peng, T.-I., Jones, D.P. and Wang, X. (1997) Prevention of apoptosis by Bcl-2: Release of cytochrome c from mitochondria blocked. Science, 275, 1129-1132. doi:10.1126/science.275.5303.1129

[57] Kluck, R.M., Bossy-Wetzel, E., Green, D.R. and Newmeyer, D.D. (1997). The release of cytochrome c from mitochondria: A primary site for $\mathrm{Bcl}-2$ regulation of apoptosis. Science, 275, 1132-1136. doi:10.1126/science.275.5303.1132

[58] Curz-Reyes, J. and Tata, J.R. (1995) Cloning, characterization and expression of two Xenopus bcl-2-like cellsurvival genes. Gene, 158, 171-179. doi:10.1016/0378-1119(95)00159-4

[59] Stack, J.H. and Newport, J.W. (1997) Developmentally regulated activation of apoptosis early in Xenopus gastrulation results in cyclin A degradation during interphase 
of the cell cycle. Development, 124, 3185-3195.

[60] Kaito, C., Kai, M., Higo, T., Takayama, E., Fukamachi, H., Sekimizu, K. and Shiokawa, K. (2001) Activation of the maternally preset program of apoptosis by microinjection of 5-aza-2'-deoxycytidine and 5-methyl-2'-deoxycytidine-5'-triphosphate in Xenopus laevis embryos. Development, Growth and Differentiation, 43, 383-390. doi:10.1046/j.1440-169x.2001.00579.x

[61] Kai, M., Kaito, C., Fukamachi, H., Higo, T., Takayama, E., Hara, H., Ohya, Y., Igarashi, K. and Shiokawa, K. (2003) Overexpression of S-adenosylmethionine decarboxylase (SAMDC) in Xenopus embryos activates maternal program of apoptosis as a "fail-safe" mechanism of early embryogenesis. Cell Research, 13, 147-158. doi:10.1038/sj.cr.7290159

[62] Shiokawa, K., Kai, M., Higo, T., Kaito, C., Fukamachi, H., Yaoita, Y. and Igarashi, K. (2000) Maternal program of apoptosis activated shortly after midblastula transition by overexpression of S-adenosylmethionine decarboxylase in Xenopus early embryos. Comparative Biochemistry and Physiology B, 126, 149-155. doi:10.1016/S0305-0491(00)00193-0

[63] Ikegami, R., Hunter, P. and Yager, T.D. (1999) Developmental activation of the capability to undergo checkpoint-induced apoptosis in the early zebrafish embryo. Developmental Biology, 209, 409-433. doi:10.1006/dbio.1999.9243

[64] Stancheva, I, EI-Maarri, O., Walter, J., Niveleau A. and Meehan, R.R. (2002) DNA methylation at promoter regions regulates the timing of gene activation in Xenopus laevis embryis. Developmental Biology, 243, 155-165. doi:10.1006/dbio.2001.0560

[65] Miyanaga, Y., Torregroza, I. and Evans, T. (2002) A maternal Smad protein regulates early embryonic apoptosis in Xenopus laevis. Molecular and Cellular Biology, 22, 1317-1328. doi:10.1128/MCB.22.5.1317-1328.2002

[66] Trindade, M., Messenger, N., Papin, C., Grimmer, D., Fairclough, L., Tada, M. and Smith, J.C. (2003) Regulation of apoptosis in the Xenopus embryo by Bix3. Development, 130, 4611-4622. doi:10.1242/dev.00489

[67] Murphy, C.R., Sabel, J.L., Sandler, A.D. and Dagle, J.M. (2002) Survivin mRNA is downregulated during early Xenopus laevis embryogenesis. Developmental Dynamics, 225, 597-601. doi:10.1002/dvdy.10194

[68] Salvesen, G.S. and Dixit, V.M. (1997) Caspases: Intracellular signaling by proteolysis. Cell, 91, 443-446. doi:10.1016/S0092-8674(00)80430-4

[69] Li, P., Nijhawan, D., Budihardjo, I., Srinivasula, S.M., Ahmad, M., Alnemri, E.S. and Wang, S. (1997) Cytochrome $\mathrm{C}$ and dATP-dependent formation of Apaf-1/caspase-9 complex initiates an apoptotic cascade. Cell, 91, 479-489. doi:10.1016/S0092-8674(00)80434-1

[70] Ona, V.O., Li, M., Vonsattel, J.P.G., Andrews, L.J., Khan, S.Q., Chung, W.M., Frey, A.S., Menon, A.S. and Friedlander, R.M. (1999) Inhibition of caspase-1 slows disease progression in a mouse model of Huntington's disease. Nature, 399, 263-267. doi:10.1038/20446

[71] Takayama, K., Higo, T., Kai, M., Fukasawa, M., Nakajima, K., Hara, H., Tadakuma, T., Igarashi, K., Yaoita, Y. and Shiokawa, K. (2004) Involvement of caspase-9 in execution of the maternal program of apoptosis in Xenopus late blastulae overexpressed with S-adenosylmethionine decdarboxylase. Biochemical and Biophysical Research Communications, 325, 1367-1375.

doi:10.1016/j.bbrc.2004.10.179

[72] Friedlander, R.M., Gagliardini, V., Hara, H., Fink, K.B., Li, W., MacDonald, G., Fishman, M.C., Greenberg, A.H., Moskowitz, M.A. and Yuan, J. (1997) Expression of a dominant negative mutant of interleukin-1beta converting enzyme in transgenic mice prevents neuronal cell death induced by trophic factor withdrawal and ischemic brain injury. Journal of Experimental Medicine, 185, 933-940. doi:10.1084/jem.185.5.933

[73] Nakajima, K., Takahashi, A. and Yaoita, Y. (2000) Structure, expression, and function of the Xenopus laevis caspase family. Journal of Biological Chemistry, 275, 10484 10491. doi:10.1074/jbc.275.14.10484

[74] Yaoita, Y. and Nakajima, K. (1997) Induction of apoptosis and CPP32 expression by thyroid hormone in a myoblastic cell line derived from tadpole tail. Journal of Biological Chemistry, 272, 5122-5127. doi:10.1074/jbc.272.8.5122

[75] Kajita, E., Wakiyama, M., Miura, K., Mizumoto, K., Oka, T., Komuro, I., Miyata, T., Yatsuki, H., Hori, K. and Shiokawa, K. (2000) Isolation and characterization of Xenopus laevis aldolase $\mathrm{B}$ cDNA and expression patterns of aldolase $\mathrm{A}, \mathrm{B}$, and $\mathrm{C}$ genes in adult tissues, oocytes, and embryos of Xenopus laevis. Biochimica et Biophysica Acta, 1493, 101-118. doi:10.1016/S0167-4781(00)00169-X

[76] Andreassen, O.A., Ferrante, R.J., Hughes, D.B., Klivenyi, P., Dedeoglu, A., Ona, V.O., Friedlander, R.M. and Beal, M.F. (2000) Malonate and 3-nitropropionic acid neurotoxicity are reduced in transgenic mice expressing a caspase-1 dominant-negative mutant. Journal of Neurochemistry, 75, 847-852. doi:10.1046/j.1471-4159.2000.0750847.x

[77] Slee, E.A., Adrain, C. and Martin, S.J. (1999) Serial killers: Ordering caspase activation events in apoptosis. Cell Death and Differentiation, 6, 1067-1074. doi:10.1038/sj.cdd.4400601

[78] Slee, E.A., Harte, M.T., Kluck, R.M., Wolf, B.B., Casiano, C.A., Newmeyer, D.D., Wang, H.G., Reed, J.C., Nicholson, D.W., Alnemri, E.S., Green, D.R. and Martin, S.J. (1999) Ordering the cytochrome c-initiated caspase cascade: Hierarchial activation of caspase-2, -3, -6, -7, -8, and -10 in a caspase-9 dependent manner. Journal of Cellular Biology, 144, 281-292. doi:10.1083/jcb.144.2.281

[79] Thornberry, N.A., Rano, T.A., Peterson, E.P., Rasper, D.M., Timkey, T., Garcia-Calvo, M., Houtzager, V.M., Novdstrom, P.A., Roy, S., Vaillancourt, J.P., Chapman, K.T. and Nicholson, D.W. (1997) A combinatorial approach defines specificities of members of the caspase family and granzyme, B. Functional relationsip established for key mediators of apoptosis. Journal of Biological Chemistry, 272, 17907-17911. doi:10.1074/jbc.272.29.17907

[80] Shiokawa, K., Takayama, E., Higo, T., Kuroyanagi, S., 
Kaito, C., Hara, H., Kajitani, M., Sekimizu, K., Tadakuma, T., Miura, K.-I., Igarashi, K. and Yaoita, Y. (2005) Occurrence of pre-MBT synthesis of caspase- 8 mRNA and activation of caspase- 8 prior to execution of SAMDC (S-adenosylmethionine decarboxylase)-induced, but not p53-induced, apoptosis in Xenopus late blastulae. Biochemical and Biophysical Research Communications, 336, 682-691. doi:10.1016/j.bbrc.2005.08.144

[81] Wallingford, J.B., Seufert, D.W., Virta, V.C. and Vize, P.D. (1997) p53 activity is essential for normal development in Xenopus. Current Biology, 7, 747-757. doi:10.1016/S0960-9822(06)00333-2

[82] Tchang, F., Gusse, M., Soussi, T. and Mechali, M. (1993) Stabilization and expression of high levels of p53 during early development in Xenopus laevis. Developmental Biology, 159, 163-172. doi:10.1006/dbio.1993.1230

[83] Hoever, M., Clement, J.H., Wedlich, D., Montenarh, M. and Knochel, W. (1994) Overexpression of wild-type p53 interferes with normal development in Xenopus laevis embryos. Oncogene, 9, 109-120.

[84] Soussi, T., Caron de Fromentel, C., Mechali, M., May, P. and Kress, M. (1987) Cloning and characterization of a cDNA from Xenopus laevis coding for a protein homologous to human and murine p53. Oncogene, 1, 71-78.

[85] Momand, J., Zambetti, G.P., Olson, D.C., George, D. and
Levine, A.J. (1992) The mdm-2 oncogene product forms a complex with the $\mathrm{p} 53$ protein and inhibits p53-mediated transactivation. Cell, 69, 1237-1245. doi:10.1016/0092-8674(92)90644-R

[86] Marechal, V., Elenbaas, B., Taneyhill, L., Piette, J., Mechali, M., Nicolas, J.C., Levine, A.J. and Moreau, J. (1997) Conservation of structural domains and biochemical activities of the MDM2 protein from Xenopus laevis. Oncogene, 14, 1427-1433. doi:10.1038/sj.onc. 1200967

[87] Shiokawa, K., Aso, M., Kondo, T., Takai, J.-I., Tashiro, K. and Igarashi, K. (2009) Polyamines and S-adenosylmethionine decarboxylase (SAMDC) in Xenopus embryos and effects of overexpression of SAMDC on Xenopus early embryogenesis. In: Dandrifosse, G., Ed., Biological Aspects of Biogenic Amines, Polyamines and Conjugates, Transworld Research Network, Kerala, 113148.

[88] Shiokawa, K., Aso, M., Kondo, T., Uchiyama, H., Kuroyanagi, S., Takai, J.-I., Takahashi, S., Kajitani, M., Kaito, C., Sekimizu, K., Takayama, E., Igarashi, K. and Hara, H. (2008) Gene expression in pre-MBT embryos and activation of maternally-inherited program of apoptosis to be executed at around MBT as a fail-safe mechanism in Xenopus early embryogenesis. Gene Regulation and Systems Biology, 2, 1-19. 